\title{
Serious Gaming for Water Resources Planning and Hazard Mitigation
}

\author{
A. Teague ${ }^{1}$, Y. Sermet ${ }^{2}$, I. Demir ${ }^{23}$, M. Muste ${ }^{2}$ \\ ${ }^{1}$ San Antonio River Authority, San Antonio, TX, USA \\ ${ }^{2}$ IIHR - Hydroscience \& Engineering, University of Iowa, Iowa City, IA, USA \\ ${ }^{3}$ Civil and Environmental Engineering, University of Iowa, Iowa City, IA, USA
}

Contact: Yusuf Sermet (msermet@uiowa.edu)

\section{Key Points:}

- A Multi-Hazard Tournament (MHT) is proposed to develop mitigation strategies for water-related hazards (e.g. flood, drought, and water pollution).

- MHT uses gamification to collaboratively minimize damages to water quality, habitat, water resources, vulnerable populations, and infrastructure.

- A case study is conducted to assess MHT's impact on informed problem solving and stakeholder education (i.e. learning and perception).

This manuscript is an EarthArXiv preprint and has been submitted for possible publication in a peer-reviewed journal. Please note that the manuscript has yet to be formally accepted for publication. Subsequent versions of this manuscript may have slightly different content. If accepted, the final version of this manuscript will be available via the 'Peer-reviewed Publication DOI' link on the right-hand side of this webpage. Please feel free to contact the corresponding author for feedback. 


\begin{abstract}
Hydrological hazards lead to a broad range of socio-economic and environmental risks. The development of a resilient community and risk reduction heavily rely on the adoption of holistic watershed master planning whereby the adaptation options consider the risk associated with individual or multiple hydrological hazards occurring simultaneously at a specific location. Such planning approaches pose multiple challenges for decision-makers including the access and manipulation of high-volume high-variety data. Moreover, modern planning approaches involve the watershed community in co-production of decision-making, hence, these approaches have to include elements of social learning and relationship building. This study introduces a serious gaming framework to assist stakeholders in the decision-making process for water resources planning and hazard mitigation. A Multi-Hazard Tournament (MHT) is described that allows the members of a watershed community to evaluate various adaptation options to develop mitigation strategies for multiple water-related hazards (e.g. flood, drought, and water pollution). The tournament offers a competitive and gamified setting for collaborative hazard risk assessment concerning minimizing damages to water quality, riparian habitat, water resources availability, vulnerable populations, and infrastructure. A web-based decision support tool is developed to provide interactive interfaces and engaging visualizations and serve as a one-stop platform to investigate the challenges presented for each damage center within its geographic context and to analyze the cost/benefit relationship for potential hazard mitigation strategies with dynamic analytics tools. Finally, a case study is presented to evaluate the effectiveness of MHT in increasing collective awareness and conceptual and practical understanding of water-related hazards and mitigation strategies.
\end{abstract}

Keywords: shared-vision planning, disaster management, serious gaming, watershed master plan, decision support system

\title{
1 Introduction
}

Hydrological hazards are defined as extreme events that occur with the movement and distribution of water and include a range of events including floods and droughts (Trajkovic et al., 2016), and present a broad range of social and environmental risks (Sofia et al, 2017). Most natural hazards involve complex interactions between hydrologic, atmospheric, biological, and geomorphic processes with human systems including the built environment (Sermet and Demir, 2020). Because of the complexity of these interactions, few hazards occur independently (Hart et al. 2018). How a community address hazards influence the success in the development of a resilient community (Raikes et al., 2019). Asymmetric adaptation, where mitigation action focuses on a single hazard at the exclusion of other hazards, can amplify the risk of other hazards. Thus, an integrated approach to evaluating and planning for multiple hazards is essential to risk reduction (Kappes, et al., 2012). 
Holistic watershed master planning identifies risk and proposes adaptation options to address a range of hydrologic hazards. However, when utilizing the large amount of information provided by the watershed master plan within hazard planning processes, groups must rapidly consume a large volume and variety of information and then make complex and multi-faceted decisions (Levy and Taji, 2007). The sheer volume and variety of data can be overwhelming to decisionmakers (Sermet and Demir, 2018) and can derail participatory planning processes. Decision support tools provide mechanisms for information exploration and multi-criteria decision analysis (Gret-Regamey et al., 2017) through interactive illustration of risk and the trade-offs between adaptation options. Previous efforts to create a stakeholder-based, or shared vision planning have utilized decision support tools in combination with serious gaming in order to improve the effectiveness of a structured planning process through watershed-scale decisionmaking, social learning, and relationship building (Carson et al., 2018). By utilizing these tools and approaches, a collaborative environment is created across professional disciplines and stakeholder backgrounds, which in turn, provides a local mechanism to create inclusive and adaptive management of hydrologic hazards.

This study introduces a serious gaming approach to assist stakeholders in the decision-making process for water resources planning and hazard mitigation. A Multi-Hazard Tournament (MHT) is described that allows the members of a watershed to evaluate various adaptation options in order to develop mitigation strategies to multiple water-related hazards (e.g. flood, drought, and water pollution). The tournament offers a competitive and gamified setting for collaborative hazard risk assessment with respect to minimizing damages to water quality, riparian habitat, water resources availability, vulnerable populations, and infrastructure. The MHT is powered by extensive hydrological, geophysical, economic, and disaster-related data for informed decisionmaking. For intuitive and convenient presentation of this large-scale data as well as to facilitate the MHT execution, a web-based decision support tool (DST) is designed and developed. The DST provides interactive interfaces and engaging visualizations to serve as a one-stop platform to investigate the challenges presented for each damage center within its geographic context as well as to analyze the cost/benefit relationship for potential hazard mitigation strategies with dynamic analytics tools. Finally, a case study is presented to evaluate the effectiveness of the MHT in increasing collective awareness and conceptual and practical understanding of waterrelated hazards and mitigation strategies.

One of the major contributions of this research is the novel tournament methodology to build understanding amongst participants how extreme events can shape a community in the short- and long-term on various aspects of watershed health and safety, to improve community awareness of planning tools, and to develop a shared vision of adaptation strategies. The surveys conducted before and after the case study clearly reflect the degree to which the tournament had an effect on the sense of individual and communal responsibility to address floods, and droughts, and water pollution. The MHT introduces a novel take on conventional decision making by enabling 
stakeholders to work collaboratively by taking the socio-economic context of hazards into account instead of merely the hydrological facet. Furthermore, the DST's dynamic and reactive state capacitate the stakeholders to deduce the most optimal strategies while dealing with budgetary, temporal, regulatory, and technical constraints in real-time.

The rest of the article is organized as follows. Section 2 provides a background for the study accompanied by a comprehensive literature review, and highlights the knowledge gap this research fulfills. Section 3 presents the Multi-Hazard Tournament, its scope, game design, and components. Section 4 describes the case study and the decision support tool that is used to deliver the tournament. Results and surveys are reported in Section 5. Section 6 interprets and analyses the results. Finally, Section 7 concludes the article with remarks and future directions.

\section{Background}

Watersheds consist of terrestrial and aquatic systems that sustain natural biogeochemical and hydrological processes that have harmoniously interacted among themselves over many millennia. The commencement of the Anthropocene has brought with it social and economic drivers that interrupted the natural interactions through land-use change and human activities at different scales. Unprecedented escalation of the human-driven interventions in both rural and urban settings was experienced in the past century and now we face multiple hazards related to water quantity and quality which pose far-reaching implications for ecosystem integrity, human health and prosperity, and climate change (Dibike \& Coulibaly, 2005). Consequently, solving a water-related problem today is a complex human-natural systems nexus whereby the use of the traditional approaches are insufficient to understand a river basin system behavior (Agliamzanov et al., 2020). Making decisions for the improvement of watersheds implies bringing together data and tools from many disparate areas, i.e., natural science, engineering, social science, economy, and governance (Demir and Beck, 2009).

Beginning in the past decades, hazard mitigation plans have been increasingly approached with customized Decision Support Systems (DSS) that adopt the architecture and technologies developed in other socio-economic domains (e.g., banking, e-commerce) (Xu et al., 2019). DSSs which are focused on watershed management have been already tested by government agencies, academic institutions, and consulting firms (Zhang, et al., 2011). The planning associated with multi-hazard mitigation faces multiple challenges, such as (1) assemblage of large amounts of data for covering the holistic view of the watershed (Sermet et al., 2020b), (2) ensuring close collaboration and clear communication between multiple heterogeneous actors (e.g., hydrologists, environmentalists, decision-makers, analysts, stakeholder) with diverse expertise and interests (Andrienko et al., 2007), and (3) capturing the feedback among multiple hazard drivers. The massive amount of data and information (Ebert-Uphoff et al., 2017) required to develop plans for multi-hazard mitigation is time- and labor-intensive if tackled with conventional methods. 
Given that the social-environmental-technology systems are currently highly integrated and interdependent, solving watershed problems require re-imaging the data structures (Demir and Szczepanek, 2017) and tools used for producing decisions (Xiang et al., 2020; Sit and Demir, 2019). The tools have to adopt holistic systems approaches with innovative strategies and technologies developed by transdisciplinary teaming frameworks that enable continuous and transparent interaction with the communities that benefit from the solutions. The last several decades experienced increasing efforts in connecting advanced integrated modeling (Belete et al., 2017) and watershed digital environments (Giordano et al., 2008; Mackay et al., 2015) with new planning and decision approaches that include participatory modeling (Maskrey et al., 2016; Hedelin et al., 2017), social learning (Evers et al., 2016), sustainable procedure framework (Hedelin, 2016). Bringing along all these tools into one seamless framework requires a new generation of problem-solving digital environments (Power \& Sharda, 2007; McIntosh et al, 2006; Power et al., 2015).

Contemporary challenges of water resource management involve difficult decision-making in the face of increasing complexity and uncertainty. Even if perfect knowledge on the processes, abundancy of data, and analysis tools are available, water management decisions ultimately involve competing values, which will only get more prominent with increasing scarcity and competition over resources (Marini et al, 2018). Consequently, an important requirement in making decisions is the long-term cooperation between all watershed stakeholders with full attention to social and intergenerational equity (Hedelin et al, 2017). Currently, there is an increased recognition that the participatory stakeholder processes are lagging the technological advancement in solving water problems (e.g., Purkey et al., 2018).

An emerging trend in the development of DSS is the application of serious gaming approach (Deterding et al., 2011; Voinov et al., 2015). Serious games have been typically designed for purposes (e.g., education, research) other than entertainment (Abt, 1970). This is a collaborative planning approach, which has been found to be an efficient and timely method that creates an engaging environment (Xu et al., 2020). Within the gaming environment, players can assume realistic roles (Hayden et al., 2007), tackle issues, devise strategies, make decisions, and get quick feedback on their actions (Newman et al., 2017) while interacting through live experiences that enable incorporation of their perspectives and reflections for social learning (Medema et al., 2016; Van der Wal et al., 2016). A well-designed serious game has the potential to not only playing the role of a learning tool, but more importantly, they may give rise to shared values and engage stakeholders with conflicting interests to cooperate towards a common goal (Akhtar et al., 2020).

Research in the decision-making science field highlights several important findings about the capabilities and limitations of serious gaming. The first inference from these studies was that 
competitive and collaborative drivers can play a role in supporting individual and group learning and decision-making (e.g., Weber et al. 2004, Sanfey 2007). The way in which decision-makers are encouraged to be either individualistic, competitive, cooperative, or altruistic in the serious gaming environment could influence how resources are used for finding a solution to the hazard mitigation. By encouraging cooperative decision-making and communication, it has been found that participants take a smaller amount of resources for themselves (Liebrand 1984). The serious game framework serves as the basis from which cooperative attitudes are carried from the serious gaming environment to the real-world environment. The second inference from the studies was that players may benefit from social learning when the serious game is used in a multi-player context (Medema et al. 2016). Engaging players through live experiences such as serious games, incorporating their perspectives and reflections, and using models to provide feedback creates an optimal environment for social learning (Van der Wal et al. 2016) and for increasing one's understanding of an array of current issues in water resource management (e.g., Medema et al. 2015). The third inference from the previous assessment studies was that in almost all games surveyed in the water resource management sector, there was a component of learning, typically aiming to educate players about the complex relationships between actions in a river basin and the natural environment (e.g., Schulze et al. 2015). These games facilitate learning about the importance of building connections within the water sector, and with other sectors (Zhou et al. 2013).

While a few studies have found that serious games offer a number of positive effects on one's perceptual, cognitive, behavioral, and motivational outcomes, as well as knowledge acquisition, there remains a lack of empirical evidence to fully support these claims (e.g. Girard et al. 2013). Furthermore, not all serious games are an effective method for game-based learning, nor are they the best strategy for every learning situation (Prensky 2001), as learning is dependent on having the appropriate context (e.g., Balsam \& Tomie 2014). Despite these drawbacks, serious games are considered viable mechanisms for learning and knowledge acquisition because of their costeffectiveness, timeliness, and/or safety factors that allow learners to experience real-world situations through simulations or trial and error (Corti 2006). Another perceived limitation of the previous serious gaming exercises is technological, i.e., that many of the previous versions have used traditional digital media (e.g., desktop applications and board games) (Undorf et al., 2020) that offer limited capabilities for simultaneous access, analytical processing, and multiplayer coordination, making them less effective for supporting the collaborative planning to solve complex environmental issues. Ideally, serious gaming environments should be designed to seamlessly integrate data management systems, multi-process models, and the tools for risk decision support (Yildirim and Demir, 2019) in a web-based environment accessible by all stakeholders through a platform-independent system. The capability to use a web browser, which allows users to remotely change the models' spatial and temporal inputs, will mark a definite progress (Neset et al., 2020). This starkly contrasts the conventional desktop-based modeling environment where only a single user was accommodated at a time. The web-based approach 
allows simultaneous intervention from, for example, researchers and policy-makers as both are interested in problem-solving (Xu et al, 2020).

\section{Game Structure \& Development}

\subsection{Purpose and Goals}

In this study, we present a serious gaming web-platform to facilitate collaborative planning for mitigating multiple water-related hazards. The platform was designed to support the U.S. Army Engineer Institute for Water Resources efforts pertaining to the Shared Vision Planning (SVP) program (IWR, 2015). The gaming application integrated a wide variety of water-related data and modeling results focused on decisions on multi-hazard risks (flooding, erosions, habitat deteriorations, municipal water supply damage, and water quality) from different perspectives (e.g., environmental and socio-economic impacts). The interactive environment was tested through a real-time training focused on community engagement and knowledge sharing. The serious gameplay (rules, traditional implementations, and its use in social learning), as developed by the U.S. Army Corps of Engineers (USACE), were delivered through the 2016 Cedar Rapids Multi-Hazard Tournament (MHT) in the Middle Cedar Basin watershed. The 36 players, 6 facilitators, and 4 referees were comprised of representatives of technical experts, decisionmakers, and stakeholders from several local, state, and federal agencies managing water resources in the Cedar River basin (Carson et al., 2018). A post-tournament survey indicates that $71 \%$ of the responders agreed that the MHT was useful for networking among stakeholders and improving communication between stakeholders. Following, $67 \%$ of the responders found the MHT was useful for creating new collaborations to address common issues while only $5 \%$ of the responders said it was not useful for that purpose. A general perception after the tournament was that the majority of participants agreed that the MHT held promise for increasing levels of trust among stakeholders.

The objectives of the San Antonio Tournament were to (a) improve participant awareness of planning tools such as the Watershed Master Plans, (b) build understanding amongst participants for the potential impacts of both extreme events and long term trends on different facets of watershed health and safety, and (c) develop shared awareness and vision of adaptation strategies. The tournament was structured for teams to collaboratively evaluate the impact of different adaptation options on flooding, water quality, riparian habitat, water resource availability, and vulnerable populations. Each team was tasked with selecting an ensemble of adaptation options that fit within a set budget given their consideration of the impacts on holistic watershed health and social acceptance. Because of inherent resource constraints reflected by limited budgets, participants evaluated the tradeoffs between spatially variable impacts throughout the watershed as well as variable effectiveness and acceptance on the various hazards throughout the watershed. 


\subsection{Tournament Actors}

A variety of roles were taken by tournament participants including players, referees, team facilitators, and announcers. The players were invited from a wide spectrum of public, private, and non-governmental organizations that represented technical expertise, management, funding, and advocacy entities active within the watershed. The players were divided into interdisciplinary teams of four members that reflected a cross-section of both technical expertise as well as organizational representation. The players used their subject matter knowledge to contribute to the team strategy. The referees were drawn from local experts and the United States Geological Survey (USGS), who represented a non-biased scientific and engineering resource for teams to help evaluate various options. The team facilitators and announcers were drawn from the tournament hosts and organizers, who were able to keep the gameplay on the track and running smoothly while at the same time facilitating stakeholder interaction, discussion, and relationship building.

\subsection{Gameplay}

At the beginning of each game session, the participants developed priorities for achieving particular goals within the wider community. This was accomplished by each team allocating percentage points to particular focus areas including flood mitigation, water quality, preservation of riparian habitat, protection of water resources, protecting vulnerable populations, and enhancement of recreational opportunities. An average of the percentage points allocated to each metric was then calculated and assigned as a weighting function for the corresponding metric. The community priorities were discussed with the participants to establish verification that the relative importance of each metric to the game mirrored their understanding of the community's priorities.

The participants played two rounds of the game representing two different scenarios including existing and future land use climate conditions. The first turn presented the existing condition scenario which represented the current land use and development, whereas the second turn presented the future condition scenario which represented project growth 30 years in the future. Each team evaluated the impacts of flooding, water quality, riparian habitat, protecting water resources, and vulnerable populations of various storms including the 20-year, 50-year, and 100year storms at preselected areas within the watershed. These preselected areas (i.e. damage centers) were previously identified in watershed masterplans as being significant areas where there is documented damage from previous flood events. During each round, the participants assessed the potential benefits and associated costs of different adaptation options on these metrics under the range of events.

The teams developed their mitigation plans with no knowledge of the climate conditions of the 30-year scenario. The game utilized random event generators for the distribution of flood events and total rainfall to determine both the number and type of extreme rainfall events, and the 
occurrence and severity of drought. This procedure is designed to challenge the teams to select adaptation options while contemplating the level of long-term risk. The teams discussed and evaluated tradeoffs between developing with mitigation options for high hazard but low-risk impacts versus addressing routine, but low hazards impacts.

\subsection{Game Components}

The hazard tournament utilized an interactive game interface prepopulated with information from local watershed master plans and environmental models associated with the development of the masterplans. The game interface includes a selection of adaptation options with the associated costs from the watershed master plans. The impacts of the adaptation options on water resources are evaluated using the models developed for the watershed master plans. The game interface provides the mechanism for a spatially explicit visualization of the costs and impacts as well as for incorporating participant plan selections into the scoring system. Figure 1 provides an overview of the MHT's game components.

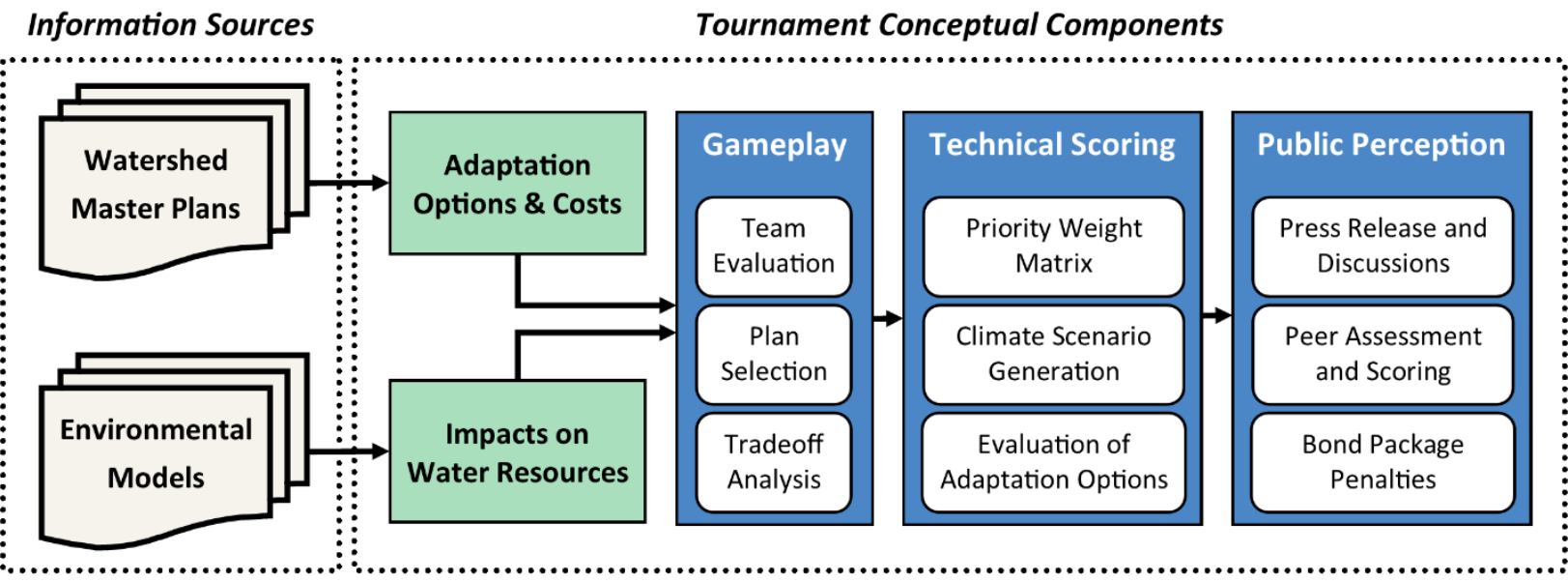

Figure 1. Game Components of the Multi Hazard Tournament

\subsubsection{Adaptation Options}

Each team could choose from adaptation options including the implementation of a capital improvement project, a stormwater infiltration and management policy, a flood protection freeboard policy, or an alternative project. In addition, the team could choose not to select any adaptation option for a damage center and create a scenario with baseline conditions for that location. The capital improvement project adaptation option represented large scale grey infrastructure projects typically implemented by governmental entities. Typical projects included flood mitigation reservoirs, channelization, or transportation-related channel work such as upsizing culverts or converting low water crossings into bridge crossings. Each capital improvement project was previously identified in the Bexar Regional Watershed Management (BRWM) Master Plans to mitigate flood risk. The cost of each different project was also 
identified in the plan. The stormwater infiltration policy option was the adaptation of a community policy requiring on-site infiltration of stormwater through development techniques such as Low Impact Development (LID) or the use of other Best Management Practices (BMPs). The cost of this adaptation option was estimated by previous efforts to identify the cost incurred by the governmental entity for activities including policy adoption, management of the regulatory framework for enforcement, and continuing community education. It was assumed that this adaptation option would result in $100 \%$ of new development implementing infiltration or other stormwater management techniques, and $25 \%$ of existing development implementing BMPs within the 30-year timeframe.

The freeboard policy is the adoption of a floodplain ordinance by the local community which requires the structures in the floodplain to have a finished floor elevation equal to the base flood elevation plus a specified freeboard. It was assumed that within the 30 -year timeframe $100 \%$ of the properties would meet the requirements of this ordinance, thus protecting the property from the impact of a flood event.

The alternative approach adaptation option was a project which utilized extensive green space or other green infrastructure areas to protect the function of the floodplain. This required buyouts of private properties within the floodplain. In addition, teams had the option to create multi-use projects with this greenspace area, by adding a recreational feature to the floodplain, such as walking and biking trails, volleyball courts, playgrounds, or other common community amenities. While not improving the flood, water quality, water resource protection, or habitat metrics, the addition of a recreation feature could improve the quality of life within the community and improve the political acceptability of such a project. The cost of these projects was estimated by the projected buyout costs and the estimated cost of park development and was assumed to be undertaken by the local governmental entities.

\subsubsection{Game Mechanics}

Budget: Each team received a budget for the 30-year investment period that constrained the level of investment. Teams were allowed to use their budget on any adaptation option at any location. Any unallocated budget from the first turn was available for use in the second turn. This allowed teams to use savings from the first turn to invest in larger cost projects that a team may not have been able to afford in a single turn. Thus, teams were required to discuss the tradeoffs of investing in projects of varying scales with varying impacts versus the risk of impact to the community. In the second turn, the teams had the option of issuing a bond package. By issuing a bond package the team was able to increase their budget with a tradeoff of a decrease in the peer score. The reduction in the peer score represented a general decrease in public satisfaction that some taxpayers might feel associated with increased taxes. The teams could select from three 
levels of bond budgets and associated peer score penalties. The larger the bond selected, the greater the peer score deduction.

Press Release: At the end of each turn, each team would present their adaptation to the tournament group in the form of a press conference. They would explain what their general approach was and how the individual adaptation selections would reduce risk and benefit the public. They focused on explaining the public acceptability of their plan, the effectiveness and impact of the plan, and the viability of making the plan actually work.

Peer Scoring: Peer scoring at the end of each turn by participants, including players and fans, provided an assessment from the taxpayer's perspective of each team's adaptation plan as presented in the press release. This provides a mechanism to evaluate the political reality of implementing the plan. Each team was scored by the other participants on three metrics including acceptability (15 points), impact (5 points), and viability (15 points).

Climate Scenarios: The performance of a team's selection of adaptation options is calculated based on a 30-year simulation of climate, with the number of 2, 10, and 100-year events as well as the number of years for drought and severe drought. The teams are not aware of the climate situation, and thus requires the players to make decisions regarding the selection of adaptation options with an unknown future. In doing so, each team needs to evaluate the risk of a range of events in terms of the tradeoffs between the costs of each adaptation option and the benefits in each of the game metrics. The climate scenario is randomly generated via a Monte Carlo simulation built upon the statistical distributions of the region's historical extreme rainfall events and average yearly rainfall.

Fundraising: Players also had the opportunity to leverage alternative funding in order to boost their budgets and increase the ability to implement additional adaptation options. Players can opt to issue a bond (i.e. public debt) that will provide additional available funds that would necessitate an increase in property taxes. The decision to increase property taxes would correspond to a decrease in taxpayer satisfaction, which would result in a penalty or automatic reduction in the peer score. Players would be able to select from a range of bond issues amounts with a corresponding peer score penalty, with greater debt corresponding to a greater penalty.

\subsubsection{Metrics and Scoring}

The scenarios created by each team through the selection of adaptation options were scored based on six metrics that reflect the priorities of the community as enumerated by the tournament players at the start of the game. These six metrics were formulated for use in the scoring and evaluation of adaptation options and as such the mathematical functions corresponding to these technical score calculations are described below along with descriptions. The variables used in 
the functions are correlated with the selected alternative, damage center, and active game round, where applicable.

Flood impact is the value of the damages resulting from the time series of rainfall events in the game simulation. The baseline floodplains and capital improvement project impacts to the floodplain were assessed using flood models previously developed in HEC-RAS as part of local master planning efforts. These models were employed to simulate each scenario by modifying the model to simulate the appropriate adaptation option or combination of adaptation options. The floodplain for each scenario was mapped and HEC- FIA (Flood Impact Analysis) software used to estimate economic losses. Flood impacts are quantified as the total structural damages accrued under a given combination of mitigatory actions (Eq. 1) for a damage center based on the climate scenario.

$$
\begin{aligned}
& \text { Flood Damages Value }(\$) \\
& \qquad \begin{aligned}
=(\text { Number of } 2 \text { year events } * 2 \text { year damages }) \\
+(\text { Number of } 10 \text { year events } * 10 \text { year damages }) \\
+(\text { Number of } 100 \text { year events } * 100 \text { year damages })
\end{aligned}
\end{aligned}
$$

The protection of water resources was assumed to be the value of groundwater recharge that could potentially improve the security of drinking water resources. Within the San Antonio River Basin, a majority of drinking water is from groundwater sources. The protection of water resources was quantified as the value of the volume of infiltrated rainwater within the 30-year simulation multiplied by the assumed value of commercial irrigation water. Local water purveyors employ differential pricing during normal and drought periods for commercial irrigation water. Therefore, the volume of water potentially infiltrated in each year was multiplied by the appropriate drought-indexed water value in order to grossly estimate the value of the change in groundwater availability for each scenario. The groundwater recharge value is, thus, formulized per damage center based on the climate scenario (Eq. 2).

$$
\begin{aligned}
& \text { Recharge Value }(\$) \\
& \quad=\text { Recharge Volume * ( Base Rate *30) } \\
& +(\text { Severe Drought Rate } \\
& * \text { Number of Severe Drought Years }) \\
& +(\text { Very Severe Drought Rate } \\
& * \text { Number of Very Severe Drought Years }))
\end{aligned}
$$

Water quality (WQ) impacts included the reduction of $E$. coli and suspended sediment exported from the drainage area, which are indicators of higher risk to the public and the environment. Reducing pollutants loading, including E. coli and TSS loading, improves the security of water resources, the quality of aquatic habitat, and recreational opportunities. Water quality improvements were quantified by determining the cost avoidance resulting from $E$. coli and TSS 
treatment measures that a like quantity of pollutant reduction would cost given implementation of treatment practices by public entities (Eq. 3).

$$
\begin{aligned}
& \text { Water Quality Damages Value }(\$)(\text { Annual }) \\
& \qquad \begin{array}{l}
\text { E. Coli Loading } \left.\left(\frac{M P N}{y r}\right) * \text { Cost of Reducing E.Coli }\left(\frac{\$}{M P N}\right)\right) \\
+\left(2000 * \text { TSS Loading }\left(\frac{\text { ton }}{y r}\right) * \text { Cost of Reducing TSS }\left(\frac{\$}{l b}\right)\right)
\end{array}
\end{aligned}
$$

The protection of riparian habitat was conceptualized as the value of preserved wetlands and riparian buffers (Eq. 4). Riparian areas provide important functions including infiltration, water quality improvements, critical habitat, and flood mitigation. The protection of these areas is vital to community resiliency. The extent of the floodplain for each scenario was used as a surrogate for area of wetland and forest and then multiplied by the per acre per year value of riparian wetlands as identified by Ingraham and Foster (2008).

$$
\begin{aligned}
& \text { Habitat Value }(\$) \\
& \qquad \begin{aligned}
& (\text { Riparian Forest Value })+(\text { Riparian Corridor Value }) \\
& +(\text { Wetland Value })
\end{aligned}
\end{aligned}
$$

The improvement or enhancement of recreational opportunities is associated with increases in property values. In the San Antonio area, the impact of greenbelts has previously been shown to increase home values by two percent (2\%) and trails with greenbelts by five percent $(5 \%)$ (Asabere and Huffman, 2007). Scenarios were evaluated for the improvements in recreation by their impact on the tax base. When buyouts were selected, the total property value of structures within a one-mile buffer of the project was assumed to increase by one percent (1\%). If a recreational investment (Table A.1), such as a picnic area, sports facility, or trail, were selected by the user, then an additional impact was calculated. The users had a list of recreational facilities from which to select as an add-on to their investment strategy. These recreational investments were classified by their reported attractiveness to communities and assigned an index ranging from 1 to $5 \%$ increases in home value. The total improvements in home values including the green space and recreational investments were calculated within the one-mile buffer and then annualized.

When flood events occur, vulnerable populations (VP) experience challenges in recovering, representing a liability to the community as a whole. Should the structures owned by economically vulnerable persons not be rebuilt or repaired, this creates an economic drain on the community which is reflected in a reduction in the tax base. Within each damage center, the percentage of households with annual incomes below the poverty level within the floodplain areas was extracted from census data (TIGER, 2010). It was assumed that this percentage of 
households would have hardship recovering from a flood event. The total appraised value of structures within each rainfall event's floodplain was multiplied by the percentage of households below the poverty line for each damage center to estimate the impact on vulnerable populations for each scenario. The impacts over the 30-year simulation of gameplay was summarized as below (Eq. 5).

$$
\begin{aligned}
& \text { Vulnerable Population Damages Value }(\$) \\
& \qquad \begin{aligned}
\text { (Number of } 2 \text { year events } * 2 \text { year VP damages }) \\
+(\text { Number of } 10 \text { year events } * 10 \text { year VP damages }) \\
+(\text { Number of } 100 \text { year events } * 100 \text { year VP damages })
\end{aligned}
\end{aligned}
$$

These metrics were utilized to assess a mitigation plan's success in terms of the avoided monetary cost. All values are normalized with respect to the damage center's baseline and expressed within the range of 0-100 (Eq. 6). The normalization process requires the negation of metrics that quantifies the damages occurring in a flood event since the benefits increase as the damages decrease. The incurred benefits are then aggregated into the Technical Score by taking the assigned weights into account (Eq. 7). Finally, the Total Score is calculated by combining the Technical and Peer Scores (Eq. 8).

$$
\text { Normalized Value }=\frac{\text { Base Value }- \text { Calculated Value }}{\text { Maximum Difference }} * 100
$$

Technical Score

$$
\begin{aligned}
& =\left(\frac{\text { Recharge Weight }}{100} * \text { Normalized Recharge Value }\right) \\
& +\left(\frac{\text { Habitat Weight }}{100} * \text { Normalized Habitat Value }\right) \\
& +\left(\frac{\text { Recreation Weight }}{100} * \text { Normalized Recreation Value }\right) \\
& +\left(\frac{\text { WQ Damages Weight }}{100} * \text { Normalized WQ Damages Value }\right) \\
& +\left(\frac{\text { Flood Damages Weight }}{100}\right. \\
& \text { * Normalized Flood Damages Value) } \\
& +\left(\frac{\text { VP Damages Weight }}{100} * \text { Normalized VP Damages Value }\right) \\
& \text { Peer Score }=\frac{(P S 1 * 15)+(P S 2 * 15)+(P S 3 * 5)}{35}
\end{aligned}
$$


Total Score $=($ Technical Score $* 0.65)+($ Peer Score $* 0.35)$

\subsection{Case Study}

The presented MHT was administered in two instances representing the upper and lower areas of watershed spanning the San Antonio River in Texas. The scope of the upper tournament was Bexar County containing the highly-populated the City of San Antonio while the lower tournament focuses on Karnes, Goliad, and Wilson Counties (i.e. Southern Counties) with predominantly rural areas. These locations have been chosen due to their historic vulnerability to recurring flooding events. For each tournament, six damage centers were identified from previous watershed master planning efforts. Table A.2 in Appendix summarizes the assessed damage centers for the upper and lower tournaments. All adaptation options, benefits, and costs concerning each tournament were predefined as external datasets that are imported into the DST. Of the 39 participants in the two tournament instances, a majority were affiliated with a local or municipal government while exactly half of all tournament players work in a sector primarily related to water resources. Approximately $60 \%$ of all participants have identified themselves in a position to be involved in the decision-making process at the advisory level for water-related hazards. Figure 2 illustrates the distribution of participant backgrounds.

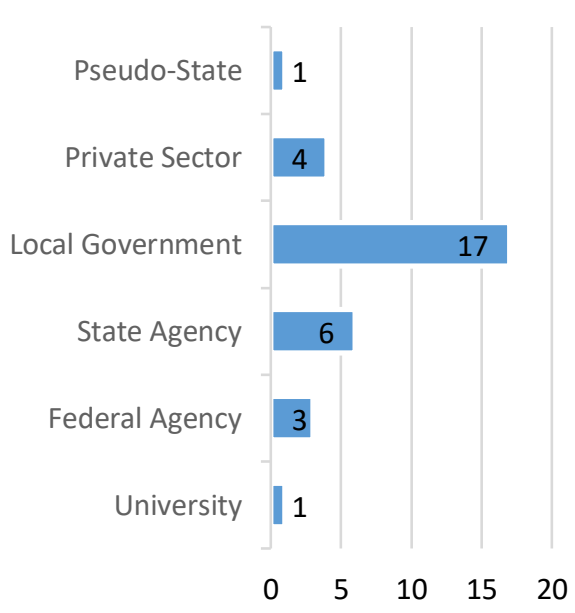

(a)

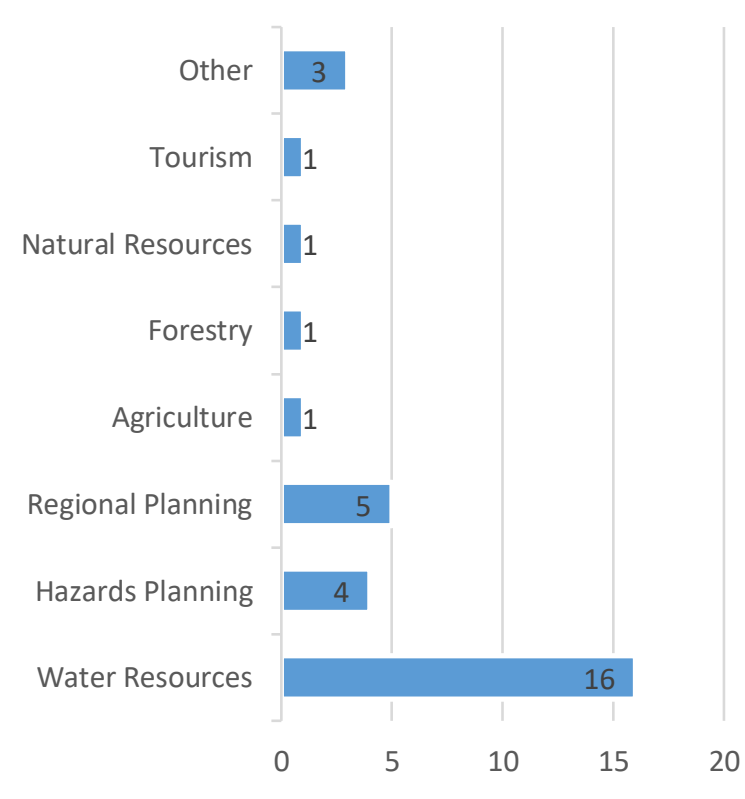

(b) 


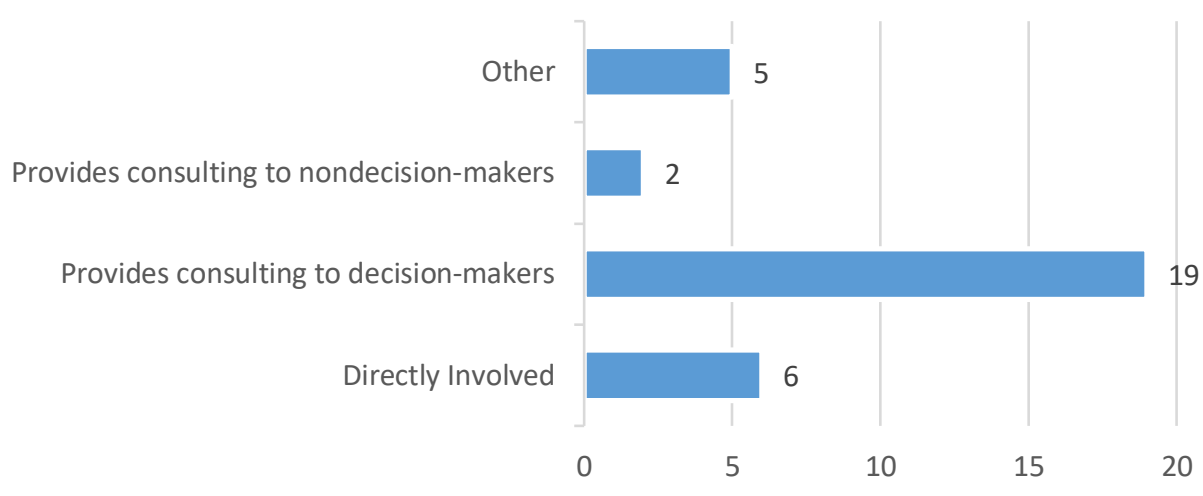

(c)

Figure 2. For all participants: (a) primary affiliation, (b) primary sectors, and (c) roles played with regard to water quality, flood, and drought related decisions.

\section{Game Delivery}

The MHT was delivered via a web-based decision support tool (DST) and administered by facilitators in-person. At the beginning of the game, the players were asked to form and register teams. Each team, as well as the facilitators, were provided internet-connected computers to access the DST, which offers different interactive interfaces for administrators and players. The DST's admin panel allows the facilitators to monitor and manage the gameplay by controlling tournament rounds, managing teams, defining metric weights matrix, setting extreme event probabilities, and assessing team-specific tournament scores. The tournament takes place in its main interface where teams log in using the pre-defined credentials. Upon the game's start, the teams utilized the DST to examine the potential benefits of any combination of mitigatory actions in terms of financial, humanitarian, and environmental impacts. Although each damage center was independently evaluated, there existed some damage centers that inherently shared common impact areas, for which the alternatives were evaluated to take into consideration overlapping effects. Once the teams were satisfied with their selections and the use of their budget, then the tournament round was concluded, and the game proceeded to scoring and discussions.

Prior to the tournament, the participants were briefed on the watershed hazards they would address in the tournament as well as the technical aspects of the DST they would use. Prior to the event, the participants were sent an introductory playbook containing materials describing the process and the tournament. The day of the event, the facilitators conducted a thorough review and Q\&A session to ensure the participants were knowledgeable of water-related hazards and challenges faced in the San Antonio Basin, motivation for risk assessment and multi-hazard planning, the scope and goals of the MHT, game mechanics (e.g. damage centers, mitigation strategies, metrics, budget), functionalities and interfaces of the DST, and an overview of the gameplay. During the tournament, on-site personnel was available to assist participants in 
domain aspects of the game as well as to immediately address any software and network related issues. Figure 3 depicts the flowchart of the game delivery from the DST perspective.

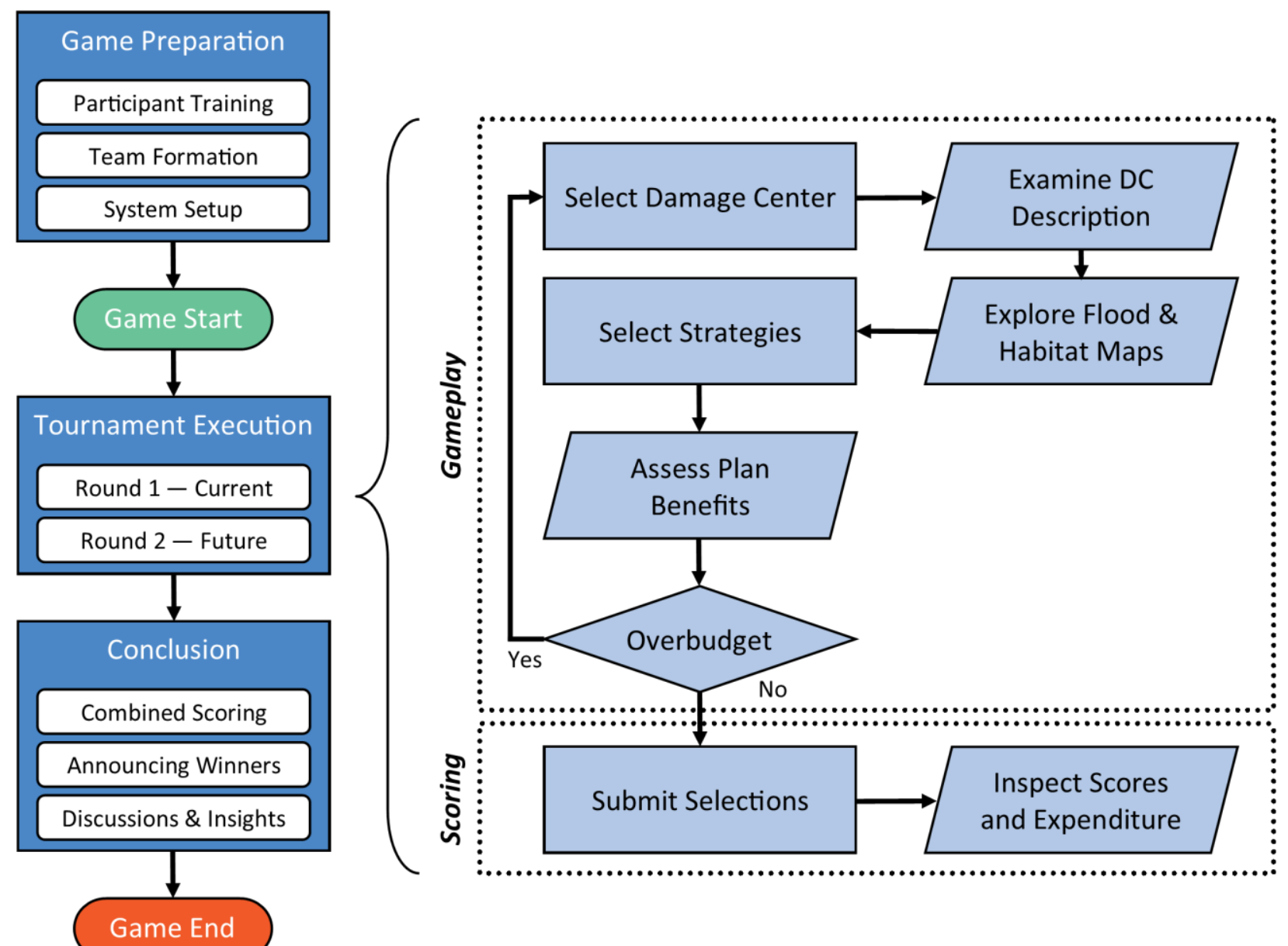

Figure 3. Flowchart describing the game delivery from the DST perspective

Within the game, participants were able to review data regarding the impact and cost of a suite of adaptation options for each of six damage centers, or sites within the watershed. Participants were able to choose capital projects, a targeted infiltration policy, enhanced floodplain protection policy, and/or buyouts to create public space with options to add recreation elements for each of the six sites. Capital projects included a variety of standard construction projects that were previously identified in the watershed master plans and included projects such as channelization, detention, or culvert improvements that would be completed by public entities. The targeted infiltration policy was an option to adopt an ordinance that would be enforced by the community to require private development and redevelopment to manage stormwater on-site with techniques such as low impact development. Enhanced floodplain protection policy was an ordinance enacted by the community to give greater protection to the floodplain and riparian area by protecting the floodplain plus one foot of freeboard. Buyouts would allow the community to purchase properties with structures within the floodplain. Participants were also able to invest in 
add-ons (i.e. recreational projects) to buyout properties in order to transform the property into public amenities, such as trails, open space, recreation, and sports facilities.

All participants have been asked to provide their inputs to prioritize different benefits in accordance with their belief to serve the community's best interest. These inputs have been aggregated for all teams to constitute a priority value to be factored in the tournament scoring as metric weights. The results have shown that the participants unanimously prioritize reducing flood damages followed by preventing impacts to vulnerable populations (Table 1).

Table 1. Summary of Priorities Selected by Participants

\begin{tabular}{lcc}
\hline Priorities & $\begin{array}{c}\text { Upper Tournament } \\
\text { (Urban) }\end{array}$ & $\begin{array}{c}\text { Lower Tournament } \\
\text { (Rural) }\end{array}$ \\
\hline Flood Damage Reduction & $24 \%$ & $28 \%$ \\
\hline $\begin{array}{l}\text { Preventing Impacts to Vulnerable } \\
\text { Populations }\end{array}$ & $23 \%$ & $21 \%$ \\
\hline $\begin{array}{l}\text { Creating Recreation Opportunities } \\
\text { Protecting and Improving Water Quality }\end{array}$ & $10 \%$ & $9 \%$ \\
\hline $\begin{array}{l}\text { Protecting and Water Resources } \\
\text { Protection and Creation of Riparian }\end{array}$ & $17 \%$ & $15 \%$ \\
\hline
\end{tabular}

\subsection{Decision Support Tool}

A web-based decision support tool (DST) was designed and developed to facilitate the gameplay for the MHT. The DST provides interactive interfaces and engaging visualizations to serve as a one-stop platform to investigate the challenges presented for each damage center within its geographic context as well as to analyze the cost/benefit relationship for potential hazard mitigation strategies. The DST allows the players to test different alternatives within budgetary limitations while being instantaneously presented with dynamically calculated plan benefits. The all-inclusive and integrated nature of the DST makes the trade-offs involved in decision-making tangible. One of the main design goals of the DST is to simplify the technical complexity of multi-hazard risk assessment and mitigation planning with effective and intuitive interfaces, and thus, to enable stakeholders to focus on the social and economic considerations for communities. The DST is comprised of two modules for use by players and facilitators: Tournament Module and Administration Module. The players interact with the Tournament Module where the serious 
gaming takes place. The main application page (Figure $4 a$ ) includes an interactive map to visualize geospatial data and several dynamic information panels. The players can choose individual damage centers to set the context. For each damage center, the players first examine the context in which flooding presents a concern for the community. Damage centers are described in terms of the problem description, traditional infrastructure, and the cost of critical infrastructure protection (CIP). Conveying the background to the players assure more informed decisions and a better understanding of how their actions decrease the need for traditional infrastructure which has substantial cost benefits. For further analysis, information source hyperlinks are provided to access various Watershed Master Plans. To aid the visual investigation of the hazards for each DC, eco-habitat and flood plain maps are drawn on the interactive map as polygons. Flood plain maps are available with 2-year, 10-year, and 100-year return periods. Mitigation strategies are presented with their respective cost in the form of checkboxes and lists. The system automatically calculates plan benefits to aid players to inspect plans with scrutiny. The provided information includes the recreational value created, total removed suspended solids in pounds and E. Coli in trillion MPN (most probable number) removed, groundwater recharge volume, gained value for riparian forest and wetland, and cost of vulnerable population and damages caused by 2-, 10-, and 100-year floods. Tooltip information boxes are available on hover to provide guidance on system usage as well as to describe environmental taxon. An overview of selections for all DCs is available to keep track of the investment and observe the consequential effects of actions due to connected DCs. Once the team is satisfied with their selections and is within the budgetary limits, they may submit their plan to be redirected to the round-end summary page (Figure $4 b$ ). The summary page is designed to offer the players a factual overview to the degree of their plan's success with interactive charts. It involves normalized benefit calculations for each DC to reflect how the plan affected the community in comparison to the spectrum defined by a DC's baseline and ideal conditions. Equal and custom weighted scores for each metric are presented to provide a perspective on the priorities of a community in terms of the value brought by different adaptation option investments. To serve as a reference, a visual summary of the plan is depicted on an interactive map and a budget utilization chart is provided. 


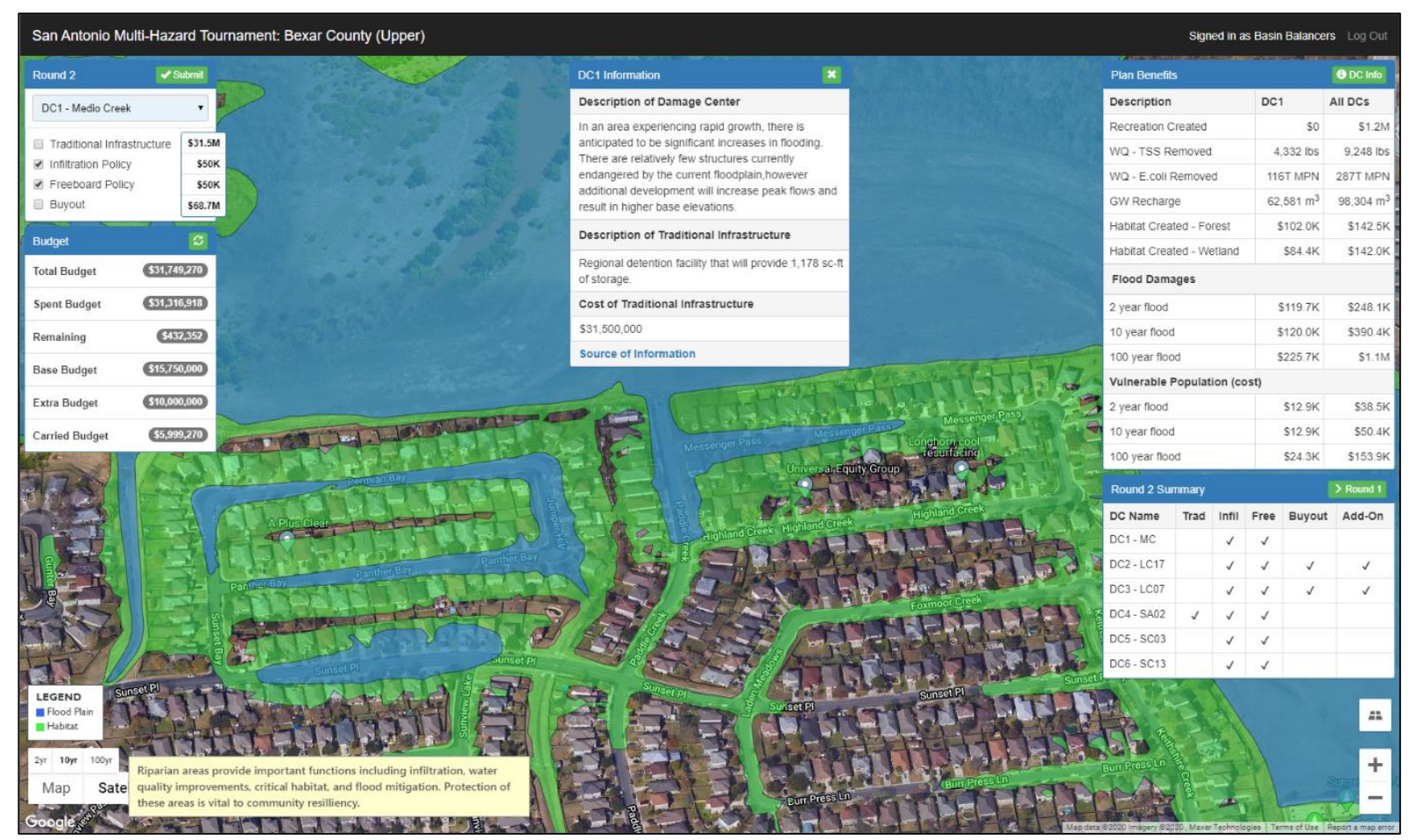

(a)

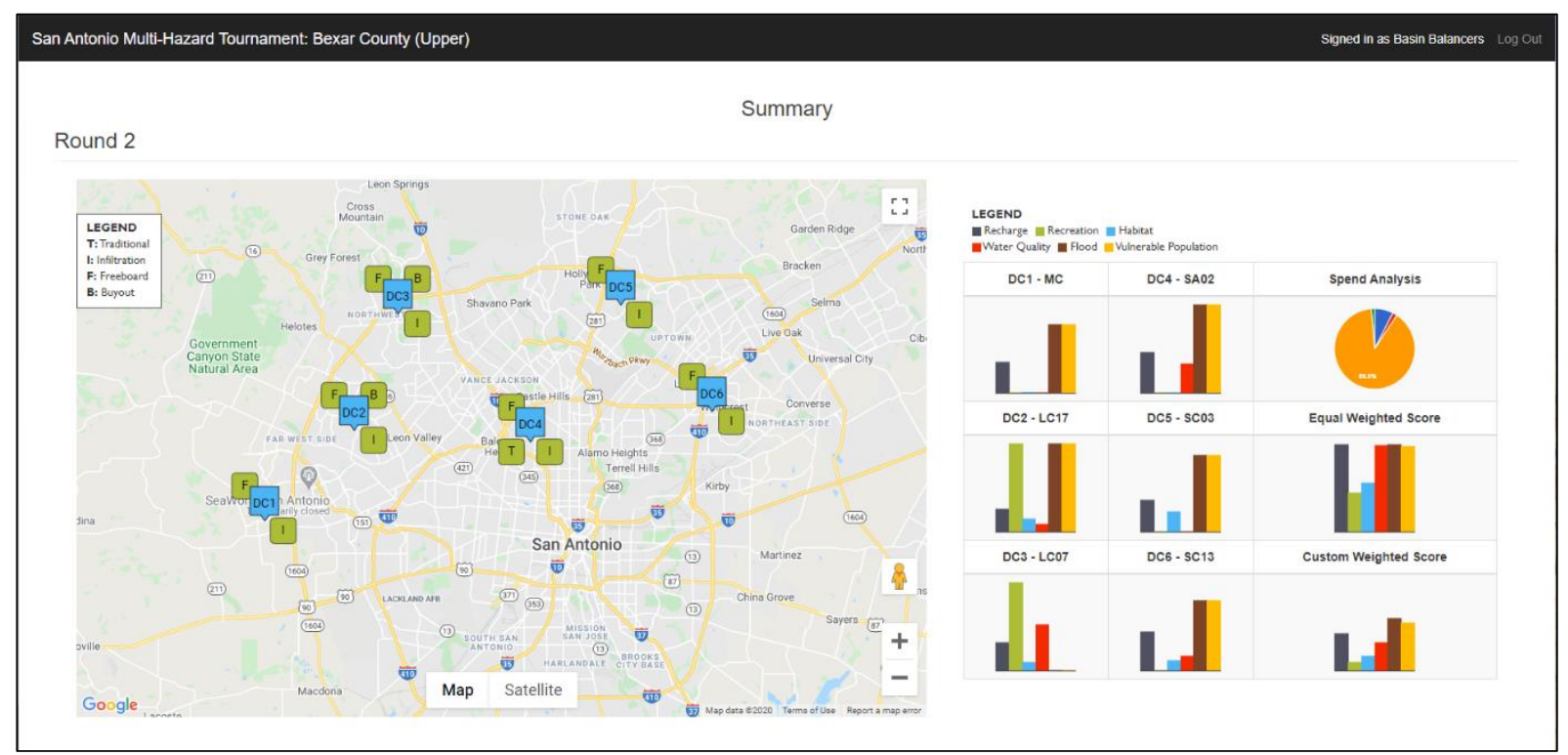

(b)

Figure 4. Screenshots from the tournament module (a) main page (b) round summary page

Administration Module provides a panel for facilitators to manage and monitor the tournament in real-time (Figure 5). The main dashboard displays the teams that have or have not submitted their selections while presenting the functionality to activate a new round. The facilitators use the panel to create, modify, and manage teams with respect to assigning credentials, issuing bonds, 
assigning peer score values, reverting accidental submissions, and disqualifying a team from the tournament if the need occurs. The weight factors, that represent a community's priorities and goals for each metric, are entered into the system via the panel to be taken into account in scoring. The generated 30-year climate scenario is inserted for both rounds in terms of the number of extreme events and drought years. Major advantages of the DST in tournament administration were the minimization of human error by automatic validation and mechanism to elucidate the degree and factors of a team's overall success. The scores are available at three different granularities. The first level offers detailed reports on each team's selections describing how their overall score is calculated at the finest level. The second level generates a visually and numerically comparable round summaries for each team to put the strengths and shortcomings of different plans into perspective. Finally, the third level presents the tournament results concisely to determine winners.

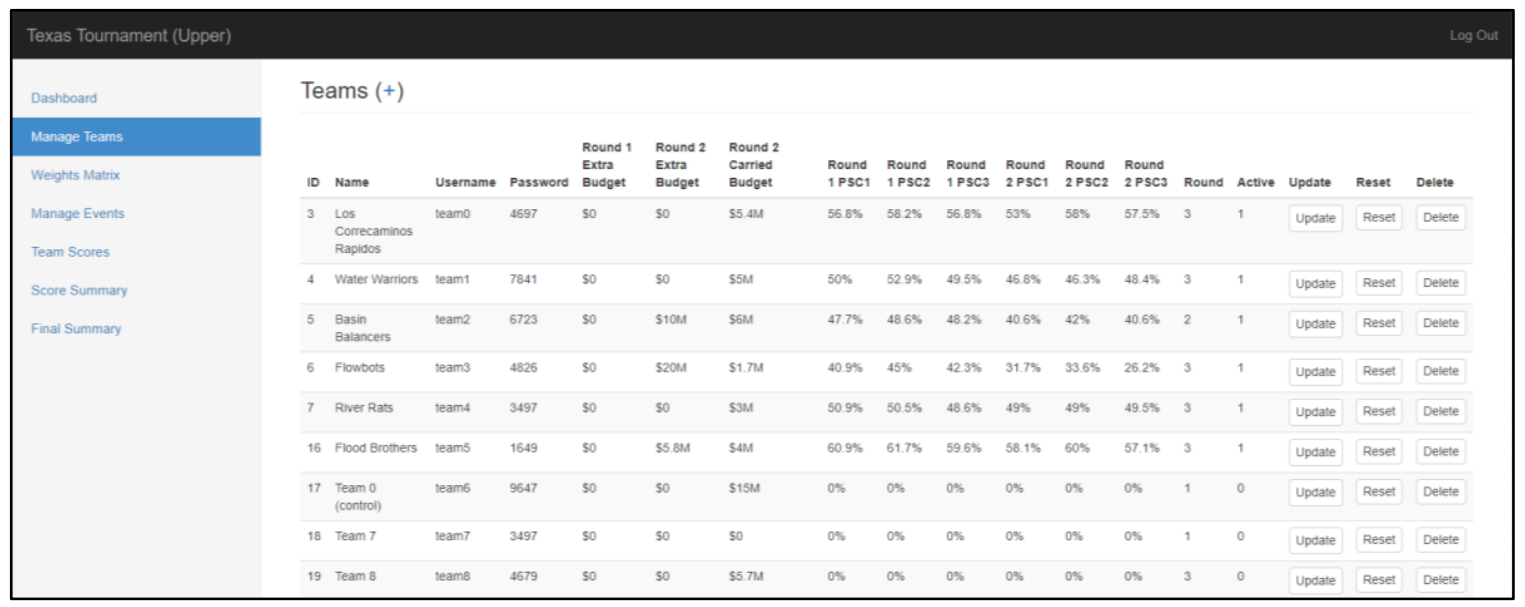

(a) 


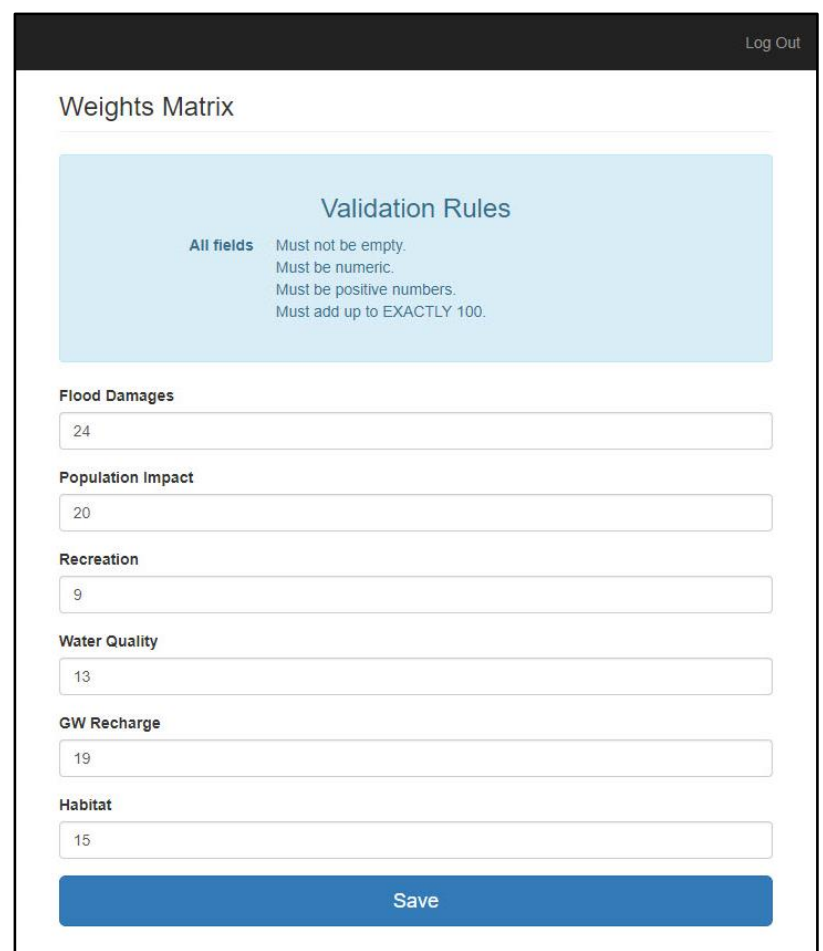

(b)

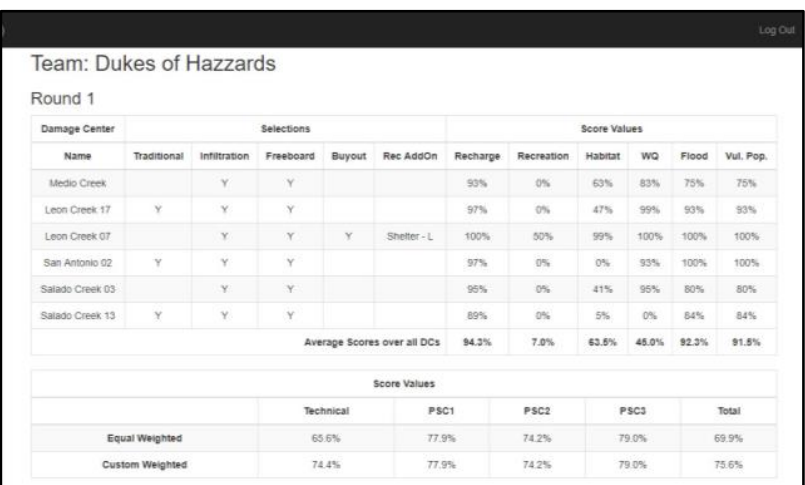

(d)

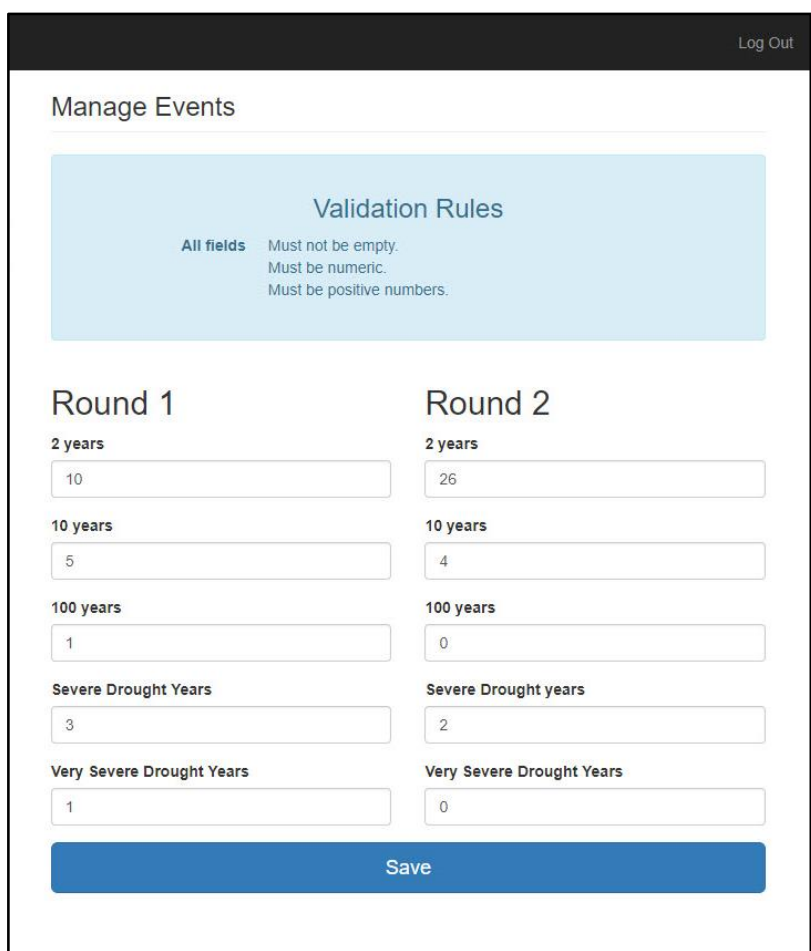

(c)

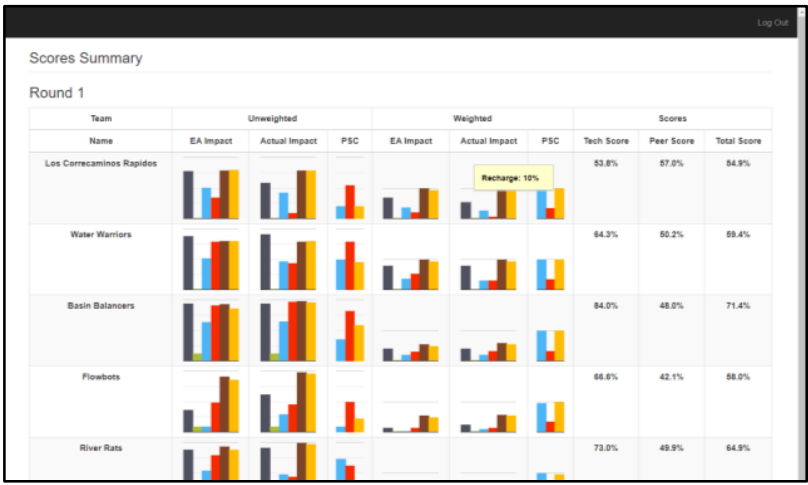

(e)

\begin{tabular}{|c|c|c|c|c|c|c|c|c|}
\hline \multirow{3}{*}{$\begin{array}{l}\text { Dashboard } \\
\text { Manage Teams } \\
\text { Weights Marri }\end{array}$} & \multicolumn{8}{|l|}{ Final Scores } \\
\hline & \multirow{2}{*}{$\begin{array}{l}\text { Team } \\
\text { Name }\end{array}$} & \multicolumn{3}{|c|}{ Round 1 scores } & \multicolumn{3}{|c|}{ Round 2 scores } & \multirow{2}{*}{$\begin{array}{c}\text { score } \\
\text { Tournament Total }\end{array}$} \\
\hline & & Tech Score & Peer score & Total Score & Tech score & Peer score & Total Score & \\
\hline \multirow{3}{*}{$\begin{array}{l}\text { Manage Events } \\
\text { Team Scores } \\
\text { Score Summary }\end{array}$} & Basin Balancers & $81.5 \%$ & $48.0 \%$ & $69.8 \%$ & $87.0 \%$ & $40.8 \%$ & $73.3 \%$ & 143.1 \\
\hline & River Rats & $70.4 \%$ & $49.9 \%$ & $63.2 \%$ & $78.7 \%$ & $49.2 \%$ & $68.6 \%$ & 131.8 \\
\hline & Water Warriors & $66.3 \%$ & $50.2 \%$ & $60.6 \%$ & $77.7 \%$ & $47.4 \%$ & $68.1 \%$ & 128.7 \\
\hline \multirow[t]{2}{*}{ Final Summary } & Los Correcaminos Rapidos & $55.1 \%$ & $57.0 \%$ & $55.7 \%$ & $78.6 \%$ & $55.6 \%$ & $71.0 \%$ & 126.8 \\
\hline & Flowbots & $62.9 \%$ & $42.1 \%$ & $55.6 \%$ & $86.8 \%$ & $29.6 \%$ & $71.1 \%$ & 126.7 \\
\hline
\end{tabular}


Figure 5. Screenshots from the admin module (a) manage teams (b) assign metric weights (c) manage events (d) team scores (e) round scores (f) tournament scores

\section{Results}

Prior to and upon the execution of the San Antonio tournament, several surveys have been employed to reflect a measurable picture of the participant experience as well as the outcomes of increasing participant awareness.

\subsection{Participant Experience}

A 5-point Likert Scale style ( 1 = Completely Disagree, 2 = Somewhat Disagree, $3=$ Neutral, $4=$ Somewhat Agree, $5=$ Completely Agree) questionnaire was utilized to assess the participant's agreement on items that measure their overall experience and satisfaction. $80 \%$ of survey-taking participants agreed that they learned information during the tournament that will inform their future decisions related to water quality, flood control, and drought management $(M=3.92)$. The responses to questionnaire items including "The tournament met my expectations", "The tournament team was responsive to my needs/questions", and "The hazard scenarios provided a realistic context for decision making." were considered as highly satisfactory and reflect a successful tournament execution $(M=4.55,4.7$, and 4.22). The playbook played a significant role in conveying the tournament goals and mechanics before and during the tournament. $78 \%$ of the participants have read the playbook prior to the event, and $88 \%$ agree that it provided about the right amount of detail or information. The participants also found the playbook useful during the tournament $(M=4.19)$. All survey respondents agreed that the Decision Support Tool was useful during the tournament $(M=4.55)$.

\subsection{Tournament Assessment}

The participants independently completed a survey prior to the start of the tournament (i.e. pretournament) and then sent a web-based follow up survey six weeks after the tournament (i.e. post-tournament). The pre-tournament survey elicited feedback regarding a participant's familiarity with existing masterplans, use of modeling for planning, and stakeholders present within the watershed (Table 2). The participants were also asked about the relative impact of flooding and drought on elements of concern within the watersheds as well as the participant's perception of the effectiveness of a variety of adaptation options (Table 3). Post-tournament, participants were asked about the impact of the tournament on their decisions and actions, including how they have used the information they were exposed to during the tournament, and how their perceptions of community roles (Table 4) and effectiveness of adaptation options has changed (Table 5).

Table 2. Pre-tournament assessment of participant familiarity with planning process

What is your familiarity with the Not at all Slightly Moderately Extremely
following?




\begin{tabular}{lcccc}
\hline $\begin{array}{l}\text { The San Antonio River Watershed Master } \\
\text { Plans }\end{array}$ & $9 \%$ & $41 \%$ & $28 \%$ & $22 \%$ \\
\hline $\begin{array}{l}\text { Using watershed planning information to } \\
\text { make decisions and plan for the future }\end{array}$ & $9 \%$ & $19 \%$ & $50 \%$ & $22 \%$ \\
\hline $\begin{array}{l}\text { Using models to make decisions and plan } \\
\text { for the future }\end{array}$ & $9 \%$ & $28 \%$ & $38 \%$ & $25 \%$ \\
\hline $\begin{array}{l}\text { The organizations responsible for } \\
\text { planning for hazards such as floods and } \\
\text { droughts, and water quality }\end{array}$ & $6 \%$ & $19 \%$ & $53 \%$ & $22 \%$ \\
\hline $\begin{array}{l}\text { How other groups of stakeholders (other } \\
\text { than my own) deal with flood and drought } \\
\text { hazards and water quality issues }\end{array}$ & $6 \%$ & $34 \%$ & $53 \%$ & $6 \%$ \\
\hline
\end{tabular}

Table 3. Comparative pre- and post-tournament assessment of participant awareness

\begin{tabular}{lcccc}
\hline $\begin{array}{c}\text { How has your familiarity with } \\
\text { the following changed? }\end{array}$ & $\begin{array}{c}\text { Less familiar } \\
\text { / comfortable }\end{array}$ & $\begin{array}{c}\text { No } \\
\text { change }\end{array}$ & $\begin{array}{c}\text { Slightly more } \\
\text { familiar / } \\
\text { comfortable }\end{array}$ & $\begin{array}{c}\text { Much more } \\
\text { familiar / } \\
\text { comfortable }\end{array}$ \\
\hline $\begin{array}{l}\text { The San Antonio River Watershed } \\
\text { Master Plans }\end{array}$ & $0 \%$ & $31 \%$ & $46 \%$ & $23 \%$ \\
\hline $\begin{array}{l}\text { Using watershed planning } \\
\text { information to make decisions and } \\
\text { plan for the future }\end{array}$ & $4 \%$ & $4 \%$ & $58 \%$ & $35 \%$ \\
\hline $\begin{array}{l}\text { Using models to make decisions } \\
\text { and plan for the future }\end{array}$ & $4 \%$ & $12 \%$ & $46 \%$ & $38 \%$ \\
\hline $\begin{array}{l}\text { The organizations responsible for } \\
\text { planning for hazards such as floods } \\
\text { and droughts, and water quality }\end{array}$ & $0 \%$ & $38 \%$ & $35 \%$ & $27 \%$ \\
\hline $\begin{array}{l}\text { How other groups of stakeholders } \\
\text { (other than my own) deal with } \\
\text { flood and drought hazards and } \\
\text { water quality issues }\end{array}$ & $0 \%$ & & & \\
\hline
\end{tabular}

Table 4. Participants' selections to most cost-effective strategies to protect and enhance water quality, limit flood damages, limit drought damages, and to achieve all three goals simultaneously

\begin{tabular}{|c|c|c|c|c|}
\hline $\begin{array}{l}\text { In your opinion, what are the } \\
\text { most cost-effective strategies? }\end{array}$ & $\begin{array}{l}\text { Protect W. } \\
\text { Quality }\end{array}$ & $\begin{array}{l}\text { Limit Flood } \\
\text { Damages }\end{array}$ & $\begin{array}{c}\text { Limit Drought } \\
\text { Damages }\end{array}$ & $\begin{array}{l}\text { All Three } \\
\text { Together }\end{array}$ \\
\hline & Post & Post & Post & Pre \\
\hline
\end{tabular}




\begin{tabular}{lcccccccc}
\hline $\begin{array}{l}\text { Capital improvement projects to } \\
\text { modify the floodplain }\end{array}$ & 11 & 10 & 17 & 15 & 9 & 8 & 17 & 15 \\
\hline $\begin{array}{l}\text { Enacting policies to encourage } \\
\text { on-site stormwater management }\end{array}$ & 23 & 20 & 18 & 16 & 21 & 22 & 21 & 21 \\
\hline $\begin{array}{l}\text { Elevating structures through } \\
\text { planning and zoning processes }\end{array}$ & 4 & 3 & 8 & 7 & 3 & 2 & 7 & 7 \\
\hline $\begin{array}{l}\text { Relocating structures through } \\
\text { planning and zoning processes }\end{array}$ & 6 & 8 & 6 & 10 & 3 & 5 & 7 & 9 \\
\hline $\begin{array}{l}\text { Developing open space with } \\
\text { recreational opportunities }\end{array}$ & 15 & 15 & 15 & 11 & 13 & 15 & 20 & 14 \\
\hline
\end{tabular}

Table 5. Participants' selections to the extent an organization should be responsible to address drought, water quality, and flood hazards

\begin{tabular}{c}
$\begin{array}{c}\text { In your opinion, to what } \\
\text { extent these groups } \\
\text { should be responsible? }\end{array}$ \\
\hline
\end{tabular}

Drought W. Quality Flood Drought W. Quality Flood

\begin{tabular}{lcccccc}
\hline $\begin{array}{l}\text { Residents and } \\
\text { Landowners }\end{array}$ & \multicolumn{7}{l}{ (1) } & & & & \\
\hline Not at all responsible & 0 & 0 & 3 & 1 & 0 & 2 \\
\hline Somewhat responsible & 7 & 6 & 11 & 10 & 8 & 8 \\
\hline Mostly responsible & 15 & 18 & 11 & 12 & 15 & 10 \\
\hline Completely responsible & 6 & 3 & 3 & 1 & 1 & 4 \\
\hline Federal Agencies & & & & & & \\
\hline Not at all responsible & 2 & 2 & 1 & 1 & 1 & 1 \\
\hline Somewhat responsible & 8 & 7 & 5 & 10 & 7 & 7 \\
\hline Mostly responsible & 10 & 10 & 12 & 8 & 10 & 10 \\
\hline Completely responsible & 7 & 8 & 9 & 5 & 6 & 6 \\
\hline State Agencies & & & & & & \\
\hline Not at all responsible & 0 & 0 & 0 & 0 & 0 & 0 \\
\hline Somewhat responsible & 6 & 3 & 4 & 4 & 2 & 2 \\
\hline Mostly responsible & 12 & 15 & 14 & 15 & 15 & 16 \\
\hline Completely responsible & 9 & 10 & 9 & 5 & 7 & 6 \\
\hline Local Governments & & & & & & \\
\hline Not at all responsible & 0 & 0 & 0 & 0 & 0 & 0 \\
\hline Somewhat responsible & 5 & 2 & 2 & 5 & 2 & 2 \\
\hline Mostly responsible & 9 & 12 & 11 & 12 & 14 & 13 \\
\hline Completely responsible & 14 & 14 & 15 & 7 & 8 & 9 \\
\hline
\end{tabular}




\begin{tabular}{lcccccc}
\hline Private Companies & & & & & & \\
\hline Not at all responsible & 1 & 1 & 1 & 0 & 0 & 1 \\
\hline Somewhat responsible & 9 & 7 & 7 & 9 & 7 & 7 \\
\hline Mostly responsible & 11 & 13 & 11 & 12 & 14 & 13 \\
\hline Completely responsible & 6 & 6 & 8 & 3 & 3 & 3 \\
\hline
\end{tabular}

\section{Discussions}

\subsection{Informed Problem Solving}

Increased Awareness of Hazards: A primary goal of the tournament was to increase awareness of partners, opportunities, and resources available to address hazards within their jurisdiction. Through post-tournament surveys, $96 \%$ of respondents reported that they met a beneficial contact and $76 \%$ of respondents identified an opportunity to coordinate. Prior to the tournament $53 \%$ of respondents were moderately familiar with how other groups of stakeholders deal with flood, drought, and water quality issues. Post-tournament surveys indicate that $52 \%$ of respondents are slightly more comfortable and $28 \%$ are much more comfortable with how other stakeholders deal with flood, drought, and water quality issues. In addition, $88 \%$ of respondents indicated that they would recommend using the tournament to increase communication between stakeholders. In fact, $54 \%$ of post survey respondents indicated that they had discussed a potential project or projects with another participant, with $84 \%$ indicating that the tournament would increase trust between stakeholders. While $50 \%$ and $27 \%$ of post-survey respondents somewhat and completely agree that the relevant stakeholders were represented at the tournament, $8 \%$ of the respondents disagreed. Policy makers, political actors, environmental representatives, and neighborhood advocates were identified as missing stakeholders who should be included in the tournament or have a targeted separate tournament.

Increased Awareness of Planning Tools: A secondary goal of the tournament was to increase awareness of planning tools available to the participants, namely Watershed Master Plans. Prior to the tournament, only $41 \%$ of respondents were slightly familiar with watershed master plans, with $28 \%$ and $22 \%$ of respondents moderately and extremely familiar. After the tournament, $23 \%$ of respondents reported that they were much more familiar with the local watershed master plans and $46 \%$ somewhat more familiar with watershed master plans. Of the respondents, 35\% reported that they were much more familiar with using the watershed master plans to assist with decision-making. Furthermore, $62 \%$ of the respondents were very likely to refer to the Master Plan for hazard mitigation projects and strategies. More broadly, $76 \%$ of respondents indicated that they would recommend the use of a tournament exercise to help develop hazard mitigation plans with $84 \%$ feeling that the tournament was helpful for identifying the costs and tradeoffs of various problem-solving strategies. In fact, multiple respondents commented that the tournament highlighted the differences between actual and perceived benefits of various strategies. According to another respondent, the game reinforced the difficulties of creating long-range plans while managing short terms goals in a non-crisis period. 


\subsection{Learning and Perception}

Pre and Post surveys also were used to assess participants' perceptions regarding the strategies and roles for addressing watershed hazards. Prior to the tournament, $97 \%$ of participants said it was very important to invest in flood control strategies, which was the highest response of the various strategies. Enhancement of recreational amenities had the lowest response pertaining to the importance of investment. After the tournament, there was no change in the respondents' perception of the importance of investment in flood control strategies. While there was little change overall in the importance that participants assigned to investing in strategies to address the identified strategies, the largest change in the importance of investment was a $14 \%$ increase in the importance of investing in drought mitigation strategies. At the same time, $6 \%$ of participants identified that recreational enhancements were less important to address. When asked about familiarity with the different adaptation options, the respondents were most familiar with capital improvement projects but lease familiar with structure relocations or buyouts. After the tournament, respondents indicated that they most increased their familiarity with structure elevations through planning and zoning or freeboard policies.

Prior to the tournament, $93 \%$ of the respondents said that local governments were mostly or completely responsible for addressing flood hazards. The greatest change in how respondents viewed responsible parties for addressing flood hazard was a $28 \%$ increase in the responsibility of residents or landowners. This is reflected by a majority of both pre- and post-tournament survey responses identifying policies to increase on-site stormwater management as the most cost-effective strategy for limiting flood damages. The greatest change from the pre- to posttournament was an increase of $7.57 \%$ in the perception of the cost-effectiveness of the relocation of structures in the floodplain (i.e. buyouts). This was followed by a $4.8 \%$ decrease in the perception of the cost-effectiveness of the development of open space with recreational opportunities.

Likewise, pre-tournament, $82 \%$ of respondents identified local government as being mostly or completely responsible for addressing drought hazards. After the tournament, the greatest change in how the respondents perceived as both less and more responsible for addressing drought was for the federal government, with $29 \%$ responding that they believed the federal government was less responsible and $14 \%$ more responsible. This reflected the change in perception of the most cost-effective strategies for addressing drought hazards. The greatest increase in perception of cost-effectiveness was for relocation of structures from the floodplain (buyouts), which within the region has historically required federal assistance. At the same time, the greatest decrease in perception of cost-effectiveness was for capital improvement projects, which have typically been funded by both local and federal funding mechanisms. Both pre- and post-tournament, respondents identified on-site stormwater management and relocation of structures, both of 
which are strategies which create opportunities for infiltration, as the most cost-effective means to mitigate drought hazards.

Respondents most strongly identified local government entities as responsible for mitigating water quality hazards prior to the tournament. After the tournament, $64 \%$ of respondents viewed the local government as being less responsible and $41 \%$ viewed the federal government as being more responsible. Although on-site stormwater management policies, which were specifically promoted in order to improve water quality was identified as the most cost-effective strategy both pre- and post-tournament, it had the greatest decrease in perception of cost-effectiveness. At the same time, the greatest increase in perception of cost-effectiveness was the relocation of structures from the floodplain, to create open space and provide stream protection buffers.

Respondents were most likely to choose policies for on-site stormwater management as the most cost-effective for simultaneously addressing flood, drought, and water quality hazards both prior to and after the tournament. The greatest increase in the perception of cost-effectiveness was for the relocation of structures, or buyout to create open space within the floodplain and the greatest decrease was for adding recreational opportunities in open space.

\subsection{Decision Support Tool and Accessibility}

Within this study, the use of DST proved to be beneficial for the participatory planning of hazard mitigation and water resources planning. Formulating realistic solutions to increase community resilience relies on complex mechanics which can be overwhelming to nontechnical stakeholders. Thus, this barrier poses a challenge in involving the members of a community in a multi-dimensional decision-making process. The DST's unique design facilitates informed, intuitive, and focused evaluation of adaptation options while freeing the stakeholders from the technical complexity in regard to the hydrological and geophysical background. A contributing factor to this facilitation is the user-oriented interfaces tasked with communicating high-volume high-dimension technical data seamlessly and effectively with real-time plan interpretation and analytics tools. Furthermore, the DST assures the integrity of the planning calculations as well as the tournament execution with its robust and tested software architecture and implementation (Sermet et al., 2020a).

\section{Conclusions}

The paper describes advances in the application of serious gaming that sensibly improve hazard mitigation planning through realistic implementation of shared vision planning by enabling communities to be directly involved in the decision-making for the future of their watersheds Use of a DST facilitated and expedited the gameplay giving to all participants a true sense of coproduction of mitigation plans for multiple hazards. The actual delivery of the multi-hazard tournament is an exemplary demonstration of a stakeholder-driven planning process, which also improved education on water resources aspects, changed participant perceptions, facilitated 
collaboration, and created a platform to openly discuss both the technical and social trade-offs and benefits of previously identified hazard mitigation adaptation options.

Whereas previous sharing of holistic planning efforts for mitigating multi-hazards have been overwhelmed by the amount and complexity of data and the explanation of intricate process interdependencies, the developed web-based DST was delivered using easy to understand visualizations that obscured the underlying complexity and allowed users of various technical skills to be part of the game. Based on user feedback, necessary improvements to the tournament structure include refinement of spatial and temporal complexity to reflect the upstream to downstream cumulative nature of impacts within the watershed as the realities of multiple communities with differing priorities and resources. In addition, users desired improvements within the DST that allowed exploration of how current investment impacts future watershed hazards and needs. While peer-scoring was utilized as a surrogate for social and political feedback mechanism, this represents an opportunity for the inclusion of non-technical audiences and players into the process, should advances in the DST and tournament evolve to incorporate these decision-makers in the social (peer) scoring structure. Overall, the tournament provided an easy to use platform for communication and organization of watershed master planning data and information and was a powerful tool for allowing stakeholders to shape a shared vision for the watershed.

\section{Acknowledgement}

This project is based upon work funded by the US Army Corps of Engineers and is the result of a collaborative effort by The Institute for Water Resources (Fort Worth District), the San Antonio River Authority, and IIHR-Hydroscience and Engineering. Special thanks to our agency colleagues Andrea Carson, Harvey Hill, and Rolf Olsen. Haowen Xu and Haider Hameed provided valuable input and assistance towards the development of the presented decision support tool.

\section{References}

Abt, C. C. (1987). Serious Games. University press of America.

Agliamzanov, R., Sit, M., \& Demir, I. (2020). Hydrology@ Home: a distributed volunteer computing framework for hydrological research and applications. Journal of Hydroinformatics, 22(2), 235-248.

Akhtar, M. K., de la Chevrotière, C., Tanzeeba, S., Tang, T., \& Grover, P. (2020). A serious gaming tool: Bow River Sim for communicating integrated water resources management. Journal of Hydroinformatics.

Andrienko, G., Andrienko, N. and Jankowski, P. (2007). Geovisual analytics for spatial decision support, International Journal of Geographical Information, 21, 839-857. 
Asabere, P. and Forrest Huffman. 2007. The Relative Impacts of Trails and Greenbelts on Home Price. Journal of Real Estate Finance and Economics. 38, DOI 10.1007/s11146-007-9089-8; 408-419.

Balsam, P. and Tomie, A. (2014). Context and learning, Psychology Press, New York, NY

Belete, G.F., Vinov, A. and Morales, J. (2017). Designing the Distributed Model Integration Framework - DMIF, Environmental Modelling \& Software, 94, 112-126.

Carson, A., Windsor, M., Hill, H., Haigh, T., Wall, N., Smith, J., Olsen, R., Bathke, D., Demir, I. and Muste, M. (2018). "Serious Gaming for Participatory Planning of Multi-hazard Mitigation," The International Journal of River Basin Management, doi:10.1080/15715124.2018.1481079.

Corti, K. (2006). Games-based learning; a serious business application, Informe de Pixel Learning, 34 (6), 1-20.

Demir, I., \& Beck, M. B. (2009, April). GWIS: a prototype information system for Georgia watersheds. In Georgia Water Resources Conference: Regional Water Management Opportunities, UGA, Athens, GA, US.

Demir, I., \& Szczepanek, R. (2017). Optimization of river network representation data models for web-based systems. Earth and Space Science, 4(6), 336-347.

Deterding, S., Dixon, D., Khaled, R. and Nacke, L. (2011). From game design elements to gamefulness: defining "gamification. In: 15th International Academic MindTrek Conference: Envisioning Future Media Environments, September 28 - 30; (Tampere, Finland).

Dibike, B.Y., and Paulin C. (2005). Hydrologic impact of climate change in the saguenay watershed: comparison of downscaling methods and hydrologic models. Journal of Hydrology, 307, 145-163.

Ebert-Uphoff, Imme, David R. Thompson, Ibrahim Demir, Yulia R. Gel, Anuj Karpatne, Mariana Guereque, Vipin Kumar, Enrique Cabral-Cano, and Padhraic Smyth. "A vision for the development of benchmarks to bridge geoscience and data science." In 17th International Workshop on Climate Informatics. 2017.

Evers, M., Jonovski, A., Almoradie, A. and Lange, L. (2016). Collaborative decision making in sustainable flood risk management: A socio-technical approach and tools for participatory governance, Environmental Science \& Policy, 55, 335-344.

Girard, C., Ecalle, J., and Magnan, A. (2013). Serious games as new educational tools: how effective are they? A meta-analysis of recent studies. Journal of Computer Assisted Learning, 29 (3), 207-219.

Giordano R., Uricchio V. F. and Vurro M. (2008). Monitoring Information Systems to Support Integrated Decision-making. Timmerman J. G., Pahl-Wostl C. and Moltgen J. (eds.), IWA Publishing, London (UK), pp. 113-129.

Gret-Regamey, A., J. Altwegg, E. Siren, M. vanStrien, B. Weibel. 2017. Integrating ecosystem services into spatial planning-A spatial decision support tool. Landscape and Urban Planning. 165: doi.org/10.1016/j.landurbplan.2016.05.003: 206-219. 
Hart, D.E., Giovinazzi, S., Byun, D.S., Davis, C., Ko, S.Y., Gomez, C., Hawke, K. and Todd, D., 2018. Enhancing resilience by altering our approach to earthquake and flooding assessment: multi-hazards. 16th European Conference on Earthquae Engineering. Thessaloniki June 2018.

Hedelin, B., Eers, M., Alkan-Olsson, J. and Jonsson, A. (2017). Participatory modelling for sustainable development: Key issues derived from five cases of natural resources and disaster risk management, Environmental Science \& Policy, 76, 185-196.

Hedelin, B. (2016). The sustainable procedure framework for disaster risk management: illustrated by the case of the EU Floods Directive in Sweden, Int. J. Risk Science, 7, doi: 10/1007/s13753-016-0093-6, 151-162

Kappes, M., M. Keiler, K. von Elverfeldt, T. Glade. 2012. Challenges of analyzing multi-hazard risk: a review. Natural Hazards.64; DOI 10.1007/s11069-012-0294-2; 1925-1958.

Levy, J. and K. Taji. 2007. Group decision support for hazards planning and emergency management: A Group Analytic Network Process (GANP) approach. Mathematical and Computer Modelling. 46(7-8):906-917. doi.org/10.1016/j.mcm.2007.03.001

Liebrand, W.B. (1984). The effect of social motives, communication and group size on behaviour in an N-person multi-stage mixed-motive game. European Journal of Social Psychology, 14 (3), 239-264.

Mackay E. B., Wilkinson M. E., MacLeod C. J. A., Beven K., Percy B. J., Macklin M. G., Quinn P. F., Stutter M. and Haygarth P. M. (2015). Digital catchment observatories: A platform for engagement and knowledge exchange between catchment scientists, policy makers, and local communities. Water Resources Research, 51, pp. 4815-4822. doi: 10.1002/2014WR016824; 4815-4822.

Marini, D., Medema, W., Adamowski, J., Veissière, S.P.I., Mayer, I. and Wals, A.E.J. (2018). Socio-Psychological Perspectives on the Potential for Serious Games to Promote Transcendental Values in IWRM Decision-Making, Water 10, doi:10.3390/w10081097

Maskrey, S.A., Mount, N.J., Thorne, C.R. and Dryden, I. (2016). Participatory modelling for stakeholder involvement in the development of flood risk management intervention options, Environmental Modelling \& Software, 82, 275-294.

McIntosh B., Voinov A., Smith C., and Giupponi C. (2006). Bridging the Gaps between Design and Use: Developing Appropriate Tools for Environmental Management and Policy, in Voinov A., Jakeman A., Rizzoli A. (Eds.), Proceedings of the iEMSs Third Biennial Meeting: "Summit on Environmental Modelling and Software" Burlington, USA, p. 6.

Medema, W., et al. (2016). Exploring the potential impact of serious games on social learning and stakeholder collaborations for transboundary watershed management of the St. Lawrence River Basin, Water, 8 (5), 175.

Neset, T. S., Andersson, L., Uhrqvist, O., \& Navarra, C. (2020). Serious Gaming for Climate Adaptation-Assessing the Potential and Challenges of a Digital Serious Game for Urban Climate Adaptation. Sustainability, 12(5), 1789. 
Newman, J.P., Maier, H.R., Riddell, G.A., Zecchin, A.C., Daniell, J.E., Schaefer, A.M., van Delden, H., Khazai, B., O'Flaherty, M.J. and Newland, C.P. (2017). Review of literature on decision support systems for natural hazard risk reduction: Current status and future research directions, Environmental Modelling \& Software 96, 378-409.

Power D. J., Sharda R. (2007). Model-driven decision support systems: Concepts and research directions. Decision Support Systems, 43(3), pp. 1044-1061.

Power D. J., Sharda R. and Burstein F. (2015). Decision Support Systems, Joh Wiley \& Sons.

Prensky, M. (2001). Digital game-based learning. St Paul, MN: Paragon House.

Purkey, D.R., Escobar Arias. M.I., Mehta, V.K., Forni, L., Depsky, N.J., Yates, D.N. and Stevenson, W.N. (2018). A Philosophical Justification for a Novel Analysis-Supported, Stakeholder-Driven Participatory Process for Water Resources Planning and Decision Making, Water 30, doi:10.3390/w10081009

Raikes, J., T. Smith, C. Jacobson, and C. Baldwin. 2019.Pred-disaster planning and preparedness for floods and droughts: A systematic review. International Journal of Disaster Risk Reduction.38(2019). doi.org/10.1016/j.ijdrr.2019.101207

Sanfey, A.G. (2007). Social decision-making: insights from game theory and neuroscience. Science, 318 (5850), 598-602.

Schulze, J., et al., 2015. Design, implementation and test of a serious online game for exploring complex relationships of sustainable land management and human well-being. Environmental Modelling \& Software, 65, 58-66.

Sermet, Y., \& Demir, I. (2018). An intelligent system on knowledge generation and communication about flooding. Environmental modelling \& software, 108, 51-60.

Sermet, Y., \& Demir, I. (2020). Virtual and augmented reality applications for environmental science education and training. New Perspectives on Virtual and Augmented Reality: Finding New Ways to Teach in a Transformed Learning Environment.

Sermet, Y., Demir, I., \& Muste, M. (2020a). A serious gaming framework for decision support on hydrological hazards. Science of The Total Environment, 728, 138895.

Sermet, Y., Villanueva, P., Sit, M. A., \& Demir, I. (2020b). Crowdsourced approaches for stage measurements at ungauged locations using smartphones. Hydrological Sciences Journal, 65(5), 813-822.

Sit, M., \& Demir, I. (2019). Decentralized flood forecasting using deep neural networks. arXiv preprint arXiv:1902.02308.

Soifa, G. G. Roder, G. Fontana, and P. Tarolli. 2017. Flood dynamics in urbanized landscapes:100 years of climate and human's interactions. Scientific Reports. 7, 40527 (2017). https://doi.org/10.1038/srep40527

Trajkovic, S., Kisi, O., Markus, M., Tabari, H., Gocic, M. and Shamshirband, S., 2016. Hydrological hazards in a changing environment: early warning, forecasting, and impact assessment. Advances in Meteorology. 2016:1-2. doi.org/10.1155/2016/2752091.

IWR (2015). How to Conduct a Shared Vision Planning Process. U.S. Army Engineer Institute for Water Resources (IWR), Report \# 10-R-6, Alexandria, VA. 
Undorf, S., Tett, S. F., Hagg, J., Metzger, M. J., Wilson, C., Edmond, G., ... \& Shoote, M. (2020). Understanding interdependent climate change risks using a serious game. Bulletin of the American Meteorological Society, (2020).

Van der Wal, M.M., de Kraker, J., Kroeze, C., Kirschner, P.A. and Valkering, P. (2016). Can computer models be used for social learning? A serious game in water management. Environ. Model. Software 75, 119-132.

Voinov, A., Kolagani, N., McCall, M.K., Glynn, P.D., Kragt, M.E., Ostermann, F.O., Pierce, A. and Ramu, P. (2015). Modelling with stakeholders - next generation. Environ. Model. Software, 77, 196-220.

Weber, J.M., Kopelman, S. and Messick, D.M. (2004). A conceptual review of decision making in social dilemmas: applying a logic of appropriateness. Personality and Social Psychology Review, 8 (3), 281-307.

Zhang, Y., Sugumaran, R., McBroom, M., DeGroote, J., Kauten, R.L. and Barten P.K. (2011). Web-based spatial decision support system and watershed management with a case study. International Journal of Geosciences, 195-203.

Zhou, Q., et al., 2013. The climate game: connecting water management and spatial planning through simulation gaming. In: J. Edelenbos, N. Bressers, and P., Scholten, eds. Water governance as connective capacity. Farnham, England: Ashgate Publishing ltd., 109-127.

Xiang, Z., Yan, J., \& Demir, I. (2020). A Rainfall-Runoff Model With LSTM-Based Sequenceto-Sequence Learning. Water resources research, 56(1).

Xu, H., Demir, I., Koylu, C., \& Muste, M. (2019). A web-based geovisual analytics platform for identifying potential contributors to culvert sedimentation. Science of the Total Environment, 692, 806-817.

Xu, H., Windsor, M., Muste, M. and Demir, I. (2020). A Web-Based Decision Support System for Collaborative Mitigation of Multiple Water-related Hazards using Serious Gaming, Journal of Environmental Management, 255.

Yildirim, E., \& Demir, I. (2019). An integrated web framework for HAZUS-MH flood loss estimation analysis. Natural Hazards, 99(1), 275-286. 


\section{Appendix A. Supplementary Data}

The following tables are the Supplementary data to this article.

Table A.1: List of recreational investments with their assigned indexes.

\begin{tabular}{lc}
\hline $\begin{array}{l}\text { Recreational } \\
\text { Opportunities }\end{array}$ & $\begin{array}{c}\text { Index (\% increase } \\
\text { in home value) }\end{array}$ \\
\hline Shelter-Small & 1 \\
Basketball-Small & 2 \\
Football & 2 \\
Open Area-Small & 2 \\
Shelter-Medium & 2 \\
Soccer-Small & 2 \\
Volleyball-Small & 2 \\
Exercise Area-Small & 3 \\
Picnic Area & 3 \\
Playground-Large & 3 \\
Shelter-Large & 3 \\
Soccer-Large & 3 \\
Track & 3 \\
Trail-Small & 3 \\
Amphitheater & 4 \\
Open Area-Large & 4 \\
Playground-Small & 4 \\
Soccer-Medium & 4 \\
Softball/Baseball-Small & 4 \\
Trail—Medium & 4 \\
Trail—Large & 5 \\
\hline
\end{tabular}

Table A.2: List of damage centers for the San Antonio MHT

\begin{tabular}{|c|c|c|c|}
\hline $\begin{array}{l}\text { Damage } \\
\text { Center }\end{array}$ & Problem Description & Traditional Infrastructure & $\begin{array}{l}\text { CIP Cost } \\
(\$)\end{array}$ \\
\hline \multicolumn{4}{|c|}{ Upper Basin MHT (i.e. Bexar County) } \\
\hline $\begin{array}{l}\text { Leon Creek } \\
07\end{array}$ & $\begin{array}{l}\text { Flooding primarily affects } \\
\text { transportation }\end{array}$ & $\begin{array}{l}\text { Channel widening, lowering of } \\
\text { existing culverts, and bridge upgrades }\end{array}$ & $11,389,000$ \\
\hline $\begin{array}{l}\text { Leon Creek } \\
17\end{array}$ & Residential flooding & $\begin{array}{l}\text { Channel widening, increased side } \\
\text { slope, and lining with concrete. }\end{array}$ & $6,790,000$ \\
\hline $\begin{array}{l}\text { Salado } \\
\text { Creek } 03\end{array}$ & $\begin{array}{l}\text { Residential flooding and } \\
\text { roadway damage }\end{array}$ & Channel widening. & $4,761,387$ \\
\hline
\end{tabular}




\begin{tabular}{|c|c|c|c|}
\hline $\begin{array}{l}\text { Salado } \\
\text { Creek } 13\end{array}$ & $\begin{array}{l}\text { Residential \& commercial } \\
\text { property flooding, } \\
\text { roadway damage. }\end{array}$ & $\begin{array}{l}\text { Channel shaping and deepening, } \\
\text { adding culverts to roadway crossing, } \\
\text { and offline detention. }\end{array}$ & $2,394,953$ \\
\hline $\begin{array}{l}\text { San } \\
\text { Antonio } 02\end{array}$ & Residential flooding & $\begin{array}{l}\text { Channel widening and reducing } \\
\text { velocities, bridge replacements }\end{array}$ & $22,524,400$ \\
\hline $\begin{array}{l}\text { Medio } \\
\text { Creek }\end{array}$ & $\begin{array}{l}\text { Future flood risk in } \\
\text { rapidly growing area }\end{array}$ & Regional detention facility & $50,000,000$ \\
\hline \multicolumn{4}{|c|}{ Lower Basin MHT (i.e. Karnes, Goliad, and Wilson Counties) } \\
\hline $\begin{array}{l}\text { Karnes } \\
\text { DC2 }\end{array}$ & $\begin{array}{l}\text { Commercial area } \\
\text { flooding, debris clogs }\end{array}$ & Bridge raising & 277,000 \\
\hline $\begin{array}{l}\text { Karnes } \\
\text { DC1 }\end{array}$ & $\begin{array}{l}\text { Residential \& commercial } \\
\text { property flooding }\end{array}$ & Channel Restoration & 360,000 \\
\hline $\begin{array}{l}\text { Goliad } \\
\text { DC1 }\end{array}$ & Residential flooding & $\begin{array}{l}\text { Vegetated Swales by residential } \\
\text { streets. }\end{array}$ & 227,000 \\
\hline $\begin{array}{l}\text { Goliad } \\
\text { DC2 }\end{array}$ & Residential flooding & Construction of a detention pond. & $1,247,000$ \\
\hline $\begin{array}{l}\text { Wilson } \\
\text { DC1 }\end{array}$ & $\begin{array}{l}\text { Overtopping at highway } \\
\text { exit }\end{array}$ & $\begin{array}{l}\text { Improved crossing by adding } \\
\text { additional culverts at the crossing }\end{array}$ & 207,532 \\
\hline $\begin{array}{l}\text { Wilson } \\
\text { DC2 }\end{array}$ & $\begin{array}{l}\text { Residential flooding and } \\
\text { roadway damage }\end{array}$ & Construction of a detention pond. & 533,027 \\
\hline
\end{tabular}

